\title{
Physicochemical and Mechanical Properties of Freeze Casted Hydroxyapatite-Gelatin Scaffolds with Dexamethasone Loaded PLGA Microspheres for Hard Tissue Engineering Applications
}

\author{
Farnaz Ghorbani ${ }^{a}$, Hanieh Nojehdehian ${ }^{b^{*}}$, Ali Zamanian ${ }^{\mathrm{c}}$ \\ a Department of Biomedical Engineering, Tehran Science and Research Branch, Islamic Azad University, \\ Tehran, Iran, P. O. box: 4515/775. Farnaz_ghorbani.1991@yahoo.com \\ ${ }^{\mathrm{b}}$ Department of Dental Materials, School of Dentistry, Shahid Beheshti University of Medical Sciences, Tehran, \\ Iran, P.O. Box: 1983963113. hanieh.nojehdehyan@gmail.com \\ c Department of Nanotechnology and Advanced Materials, Materials and Energy Research Center, Karaj, Iran, \\ P. O. box: 14155-4777. a-zamanian@merc.ac.ir \\ Correspondence to: Hanieh Nojehdehian, Tel: (+98) 912-5498634, E-mail: hanieh.nojehdehyan@gmail.com
}

\begin{abstract}
Hydroxyapatite (HA)-gelatin scaffolds incorporated with dexamethasone-loaded polylactic-co-glycolic acid (PLGA) microspheres were synthesized by freeze casting technique. Scanning electron microscopy (SEM) micrographs demonstrated a unidirectional microstructure and a decrease in the pore size as a function of temperature gradient. Higher amounts of HA resulted in a decrease in the pore size. According to the results, at lower cooling rates, the formation of a lamellar structure decreased the mechanical strength, but at the same time, enhanced the swelling ratio, biodegradation rate and drug release level. On the other hand, higher weight ratios of HA increased the compressive strength, and reduced the swelling ratio, biodegradation rate and drug release level. The results obtained by furrier transform infrared spectroscopy (FTIR) and bioactivity analysis illustrated that the interactions of the materials support the apatite formation in the simulated body fluid (SBF) solution. Based on the obtained results, the synthesized composite scaffolds have the necessary mechanical and physicochemical features to support the regeneration of defects and to maintain their stability during the neo-tissue formation.
\end{abstract}

Keyword: Scaffold, Microsphere, Dexamethasone, Hard Tissue Engineering, Freeze Casting, Drug Delivery. 


\section{Introduction}

Every year, a large number of people suffer from bone defects mainly caused by agerelated conditions, disease or trauma. Due to the complications such as immune rejection and resource constraints arising from autograft and allograft sources, tissue engineering was developed to replace the failing or malfunctioning body tissues by employing a combination of desirable cells, scaffolds and signaling molecules [1]. The main focus of tissue engineering is mimicking natural extracellular matrix (ECM), composed of collagen matrix and HA as the dispersed phase in the skeletal system [2]. However, functionality of the repaired tissue is the critical issue of the regeneration process.

Various biocompatible materials with non-toxic by-products are employed to fabricate interconnected porous scaffolds [1]. A vast number of cellular scaffolds are obtained from mixtures of ceramic materials (hydroxyapatite [3-7] and bioglass [8]) and polymers (chitosan [9-12], elastin [13], alginate [14], gelatin [6,15-19] and collagen [20,21], polylactic-coglycolic acid [19,22,23], polycaprolactone [24]). Biodegradable polymers have been widely used as drug delivery systems [25-27]. PLGA is the most well-known and extensively studied biodegradable polymer used as a delivery vehicle. Due to their resemblance to ECM, biocompatible and biodegradable natural proteins, such as collagen the main structural protein found in the bone extracellular matrix, support cellular proliferation with the highest efficiency. Gelatin, the denatured form of collagen, is biocompatible, biodegradable, nonimmunogenic and cost-effective and has been used in research [28]. Calcium phosphate ceramics, particularly macroporous HA, are ideal for bone tissue engineering due to their similarity to the mineral parts of the bone $[29,30]$.

There are several methods to fabricate tissue engineering scaffolds; such as freeze casting [3,4,6,18,31-34], freeze drying [17,35,36], electrospinning [24,37-41], gas foaming [42], and phase separation [43-45]. Freeze casting is a useful technique to produce unidirectional porous ceramic or/and polymeric constructs. This method uses rapid freezing of a liquid suspension in an isolated mold by applying liquid nitrogen, followed by the sublimation of the frozen liquid phase under vacuum to fabricate an anisotropic porous microstructure. Fabrication of a lamellar structure is possible by controlling the growth direction of the ice crystals [7].

Deville et al. demonstrated that porous scaffolds with at least $40 \%$ to $65 \%$ porosity can be obtained by targeted freezing of HA suspensions and ice sublimation. The resultant porosity was open and unidirectional, exhibiting a lamellar morphology. Freezing rate and 
concentration of suspension affect pore size distribution; additionally, due to their lamellar architecture and the pore shape anisotropy, the processed scaffolds exhibited unusually high compressive strength [7]. Since the freeze casting can be used for any type of ceramic or polymeric material, freeze-cast structures can support the regeneration of a wide range of damaged tissues. Moreover, with water as the solvent, the process is environmentallyfriendly. Regarding mechanical properties, the compressive strength values can be extremely high along the ice growth direction. Furthermore, a favorable biological response to these types of scaffolds has been reported (the proliferation of preosteoblastic cells in pore channels with diameters of 25 and $100 \mu \mathrm{m}$; the regeneration of femoral bone cavities of rabbits after implantation of HA scaffolds) [46]. Arabi et al. employed freeze casting method to fabricate highly porous gelatin scaffolds using different gelatin concentrations and freezing rates. They reported that pore shapes changed from oblate and polygon to almost round at higher gelatin contents, and that the cooling rate had no obvious effect on the pore morphology. The compressive strength of the scaffolds, in contradistinction to their swelling behavior, increased as a function of cooling rate and gelatin concentration. [6]. Farhangdoust et al. studied the behavior of HA freeze-cast scaffolds using different initial concentrations, cooling rates and sintering conditions. They reported that the porosities were aligned along the freezing direction, which was parallel with the length of the samples. The formation of lamellar type porosities can be controlled via the initial concentrations of the HA slurry and the cooling rate; in addition, this microstructure improves the mechanical strength of the scaffolds by bridging the frozen layers. Therefore, this method can be easily utilized to synthesize scaffolds with other calcium phosphates or any other material [3]. Tiğlı et al., investigated the anti-inflammatory efficiency of dexamethasone-loaded chitosan scaffolds in reducing the side effects associated with the systemic delivery in cartilage development [47]. Martins et al. demonstrated the osteogenic influence of dexamethasone on bone marrow mesenchymal stem cells differentiation. Increasing the dexamethasone content of the nanofibers resulted in an increase in the concentration of alkaline phosphatase and deposition of mineralized matrix. In addition, the expression of osteoblastic markers proved the osteogenic inducing potential of nanofibrous scaffolds [48]. Son et al. demonstrated the osteoinductivity of HA/DEX-loaded PLA biphasic combination scaffolds. An increased alkaline phosphatase concentration and higher amounts of proteins and calcified bone tissue were observed in dexamethasone-loaded samples in comparison with the control groups (free of dexamethasone), suggesting that the drug-loaded biphasic scaffolds might be applicable as scaffolds for bone regeneration [49]. Also, based on Das, Son and Hickey investigations both 
in-vitro and in-vivo analysis showed that freezing operation have no negative effect on bioactivity of DEX, due to formation of new bone in defect site [50-52].

In this study, dexamethasone-containing PLGA microspheres were fabricated by solvent evaporation technique. Then, HA-gelatin scaffolds incorporated with dexamethasone-loaded PLGA microspheres were constructed by freeze casting method. The mechanical and physicochemical features were then evaluated. Freezing of the samples was carried out using different cooling rates and varying amounts of HA in order to study the resultant properties and to determine the structure which possesses the necessary features for producing a favorable biological response and supporting ossification and bone regeneration.

\section{Materials and Methods}

\subsection{Materials}

Hydroxyapatite $\left(\mathrm{HA}, \mathrm{M}_{\mathrm{w}}=502.32 \mathrm{gr} / \mathrm{mol}\right)$ and Gelatin $\left(\mathrm{M}_{\mathrm{w}}=40-50 \mathrm{kDa}\right)$ were purchased from Merck Co. Ltd. (Germany), Poly lactic acid-co-glycolic (PLGA, RG 504 H, Mw 3800054000) and Poly vinyl alcohol (PVA) (87-89\% hydrolyzed, mol. wt. 31,000-50,000 g/mol) was purchased from Sigma Co. Ltd. (USA). Dexamethasone was purchased from Sina Drau Co. Ltd. (Iran). All chemicals were used directly without further purification.

\subsection{Preparation of PLGA Microspheres}

The most commonly used method for preparing PLGA microspheres is the solvent evaporation technique based on the formation of a double emulsion (water-in-oil-in-water). Therefore, in this study, PLGA microspheres were prepared by solvent evaporation, water-inoil-in-water technique. Briefly 100mg of PLGA were dissolved in $500 \mu$ chloroform with 10 mg Dexamethasone. This polymer solution was combined with $2 \mathrm{ml}$ of a $2 \%(\mathrm{w} / \mathrm{v})$ solution of PVA in double-distilled water $\left(\mathrm{ddH}_{2} \mathrm{O}\right)$ and homogenized (homogenizer, Silent Crusher $\mathrm{M}$, SilentCrusher M, Heidolph, Germany) for $2 \mathrm{~min}$. This emulsion was then added to a $30 \mathrm{ml}$ of stirring $0.2 \%(\mathrm{w} / \mathrm{v}) \mathrm{PVA} / \mathrm{ddH}_{2} \mathrm{O}$ and continued to be stirred for $4 \mathrm{~h}$. The microspheres were then collected via centrifugation using a centrifuge set at $11,000 \mathrm{rpm}, 4{ }^{\circ} \mathrm{C}$, for $10 \mathrm{~min}$. The PLGA microspheres were then washed twice with ddH2O and centrifuged under the previously stated conditions. The resulting microspheres were then freeze-dried for 48 hours and stored at $-20^{\circ} \mathrm{C}$ before use [53]. 


\subsection{Preparation of Scaffolds}

HA-Gelatin scaffolds were fabricated by freeze casting technique. The solutions were prepared by dissolving 3\% (w/v) gelatin, 15, 30 and 50\% (w/w) HA and 4.5\% (w/w) PLGA microsphere in deionized water at $40{ }^{\circ} \mathrm{C}$ for more than 5 hours to achieve homogeneous composite solution. Moreover, $0.5 \%$ (w/w) glutaraldehyde-gelatin [6]was added to the solutions before freezing operation for cross linking reactions. In freeze casting technique, freezing operation done by home-made machine as described previously [3,4,6,18,31-34]. Therefore, solutions were transferred to polytetrafluoroethylene (PTFE) mold with an inner diameter of $10 \mathrm{~mm}$ and $50 \mathrm{~mm}$ height that placed on a circular copper rod. Bottom of this rod is placed into a liquid nitrogen tank. Moreover, a heater is connected to the rod that is joined to a proportional-integral-derivative (PID) controller. The solutions were poured into molds with $20 \mathrm{~mm}$ height and freezing occurs at the rate of 1 and $4{ }^{\circ} \mathrm{C} / \mathrm{min}$. Then frozen samples were transferred into freeze-dryer (FD-10, Pishtaz Engineering Co. Iran) and lyophilized at temperature of $-58{ }^{\circ} \mathrm{C}$ and pressure 0.5 torr for 48 hours to ensure that all the ice crystals were completely sublimated. Finally, all the crosslinked constructs was soaked in $\mathrm{NaBH}_{4} 1 \%$ and then in deionized water for 2 hours and 30 minutes; respectively, to remove unreacted glutaraldehyde [54] and prevent cytotoxicity. After that, scaffolds were frozen and transfer to freeze-dryer under mentioned conditions to prevent pore deformation after soaking. Table 1 shows abbreviation of different scaffolds.

\subsection{Characterization of Freeze-Cast Scaffolds}

\subsubsection{Morphology Observation}

The morphological and microstructural study of the both freeze casting HA-gelatin scaffolds and PLGA microspheres were characterized by scanning electron microscopy (SEM, Stereoscan S 360-Leica, UK) at an accelerating voltage of $20 \mathrm{kV}$. All samples were coated with a thin layer of gold in double 30 second consecutive cycle at $45 \mathrm{~mA}$ to reduce charging and produce conductive surface.

The average diameters of microspheres and resulting pores were analyzed by software image measurement (KLONK Image Measurement Light, Edition 11.2.0.0) [55]. At least five different SEM micrographs and 25 measurements at each image were tested to determine average and standard deviation. The apparent density of the freeze casting scaffolds was accurately measured by using density bottle method. An average of five measurements was taken for each sample. The porosity of scaffolds was calculated by using the equation 1 :

Porosity $(\%)=1-\left(\boldsymbol{\rho}_{\text {Scaffold }} / \boldsymbol{\rho}_{\text {Solid }}\right) * 100$ 
Where $\rho_{\text {scaffold }}$ is the density of the freeze drying scaffold, $\rho_{\text {solid }}$ is the density of the bulk polymer [56].

\subsubsection{Fourier Transform Infrared Spectroscopy (FTIR)}

Chemical characteristics of the composite scaffolds were evaluated by both the fourier transform infrared spectrophotometer (FTIR, Nicolet Is10, USA). For FTIR analysis, $1 \mathrm{mg}$ of the scraped samples was carefully mixed with $300 \mathrm{mg}$ of $\mathrm{KBr}$ (infrared grade) and pelletized under vacuum. Then, pellets were analyzed between 400 and $4000 \mathrm{~cm}^{-1}$ with a resolution of $4.0 \mathrm{~cm}^{-1}$ and 8 scans [57].

\subsubsection{Phase Analysis}

Phase analysis of the sintered HA-gelatin scaffolds was determined by using a X-ray diffraction (XRD, Philips $\mathrm{PW} 3710$ ) with monochromatic $\mathrm{Cu}-\mathrm{K} \alpha$ radiation under the operating conditions of $40 \mathrm{kV}$ and $30 \mathrm{~mA}$. Comparison of XRD patterns with JCPDS standards was carried out to identify the crystalline phases[4].

\subsubsection{Mechanical Behavior}

Mechanical properties of the scaffolds were determined by a universal tensile strength test system (Santam, STM 20, Iran) with a cross-head speed of $0.5 \mathrm{~mm} / \mathrm{min}$. All the samples were cut into $12 \mathrm{~mm}$ height. At least five samples were analyzed for each type of scaffolds to calculate average and standard deviation [58].

\subsubsection{Differential Scanning Calorimetry}

DSC analysis of composite scaffolds was carried out by DSC (DSC1 Star system, METTLER TOLEDO, Swiss). The temperature was increased from room temperature at heating rate of $10^{\circ} \mathrm{C} / \mathrm{min}$ to $600^{\circ} \mathrm{C}$.

\subsubsection{Swelling Ratio}

The water adsorption capacity of HA-gelatin scaffolds was determined by swelling ratio test. Thus, the samples were cut, weighted and dipped in $20 \mathrm{ml}$ phosphate buffered saline (PBS, $\mathrm{pH}=7.4$ ) at $37 \pm 0.5{ }^{\circ} \mathrm{C}$ for $2,4,6,24$ hours. Then the water on the specimen surface was removed with filter paper and the specimen was weighed in wet condition. The swelling ratio was calculated according to the equation 2:

Swelling ratio $(\%)=\left[\left(\mathrm{W}-\mathrm{W}_{0}\right) / \mathrm{W}_{0}\right]^{*} 100$

Where $\mathrm{W}_{0}$ is the initial weight and $\mathrm{W}$ is the wet weight of sample. Each swelling experiments were repeated five times to determine average and standard deviation [59].

\subsubsection{Hydrolytic Biodegradation}

To determine biodegradation rate of samples; first, the scaffolds were weighed respectively to get the initial dry weight $\left(\mathrm{W}_{0}\right)$; then, the pieces were immersed in an ampoule 
with $20 \mathrm{ml}$ PBS ( $\mathrm{pH}=7.4$ ); then, the ampoule was placed in thermo shaker (LS 500, Germany) with rotational speed $30 \mathrm{rpm}$ and constant temperature at $37 \pm 0.5{ }^{\circ} \mathrm{C}$ for four weeks. At the end of each week, the sample was taken out, washed with distilled water, freeze-dried (temperature about $-58{ }^{\circ} \mathrm{C}$ and pressure 0.5 torr for 24 hour) and weighed (W), while the PBS solution was updated weekly [17]. The biodegradation ratio was calculated according to the equation 3 :

Biodegradation ratio $(\%)=\left[\left(\mathrm{W}-\mathrm{W}_{0}\right) / \mathrm{W}_{0}\right]^{* 100}$

Where $\mathrm{W}_{0}$ is the initial weight and $\mathrm{W}$ is the dry weight of samples. Each biodegradation experiments were repeated five times to determine average and standard deviation [60].

\subsubsection{Bioactivity Analysis}

To assess the ability of hydroxyapatite (HA) formation on the surface of prepared scaffolds, the drug loaded scaffolds were placed in a falcon containing $20 \mathrm{ml}$ simulated body fluid $(\mathrm{SBF}, \mathrm{pH}=7.4)$ under shaking at $37 \pm 0.5{ }^{\circ} \mathrm{C}$ and rotational speed $30 \mathrm{rpm}$ (Thermoshaker, LS-100, Thermo Scientific, USA) for 7 and 14 days. The SBF solution was prepared according to the procedure described by Kokubo et al [61] and refreshed every 2 days. At the end of each time point, the sample was taken out, washed with distilled water and freeze-dried (temperature about $-58{ }^{\circ} \mathrm{C}$ and pressure 0.5 torr for 24 hour) to keep their structure. The surface morphology and phase analysis of the samples were evaluated using SEM-EDX and X-ray diffraction (XRD) after soaking in the SBF solution, respectively [62]. Phase analysis of the composite scaffolds was conducted using a XRD (XRD, Philips PW3710) with monochromatic $\mathrm{Cu}-\mathrm{K} \alpha$ radiation under the operating conditions of $40 \mathrm{kV}$ and $30 \mathrm{~mA}$ after 7 days immersing in SBF. Comparison of XRD patterns with JCPDS standards was carried out to identify the crystalline phases. The morphological and microstructural study of the apatite formation on scaffolds after 14 days immersing in SBF were characterized by SEM-EDX (SEM, Vega3, TESCAN, Czechoslovakia) at an accelerating voltage of $15 \mathrm{kV}$. All samples were coated with a thin layer of gold in double 30 second consecutive cycle at $45 \mathrm{~mA}$ to reduce charging and produce conductive surface [31].

\subsubsection{Dexamethasone Release Behavior}

To determine the actual drug content the drug loaded microspheres was dissolved in 2,2,2-trifluoroethanol (TFE) [63] and the actual amount of dexamethasone was measured by using a UV-Vis spectrometer at a wavelength of $304 \mathrm{~nm}$ (t80+, PG instruments Ltd, UK). 15 $\mathrm{mg}$ of scaffolds which contain dexamethasone loaded PLGA microspheres were placed in a falcon containing $2 \mathrm{ml}$ PBS ( $\mathrm{pH}=7.4$ ) under gently shaking at $37 \pm 0.5{ }^{\circ} \mathrm{C}$ and rotational speed $30 \mathrm{rpm}$ (Thermoshaker, LS-100, Thermo Scientific, USA) [64]. The concentration of 
released in the medium was evaluated over time using an UV-Vis spectrophotometer at a wavelength of $304 \mathrm{~nm}$. The medium was exchanged with fresh medium after each measurement on days 3, 7, 10, 14 and 21 [53]. Scaffolds with PLGA microspheres which are free of dexamethasone were selected as blank solution under mentioned condition. This experiment was repeated for five samples to calculate average and standard deviation.

\subsection{Statistical Analysis}

All the data were presented as mean \pm standard deviation of at least 5 experiments. Statistical analysis was performed by one-way ANOVA and Tukey's test, with significance reported when $\mathrm{p} \leq 0.05$. Also for investigation of group normalizing, Kolmogorov-Smirnov test was used.

\section{Results and Discussions}

\subsection{Morphology observation}

The microstructure depends on many different parameters such as interaction and permeability of scaffolds, and density of cells [65]. The architecture of scaffolds is of critical importance in tissue engineering applications. Interconnected porous structure of scaffolds should mimic extra-cellular matrix to support cellular penetration and the consequent diffusion of nutrients and excretion of cellular waste products [66]. Freeze casting technique consists of a freezing process and sublimation of ice crystals. As a consequence, by sublimating ice crystals of solvent, desirable lamellar porous microstructure will be formed [36].

The pore size distribution and surface morphology of the microspheres and freeze casting scaffolds were investigated by SEM. Figure 1 illustrates SEM micrographs of the-drug loaded PLGA scaffolds. The results showed that microspheres were spherical in shape, and had a regular surface $[10,53,67,68]$ without any cracks and they distributed in the range of 10 $-60 \mu \mathrm{m}$ (Figure 5). The schematic of the formation of ice crystals in freeze casting process is shown in Figure 2.

Figure 3 (a-1) demonstrates the SEM micrographs of HA-gelatin scaffolds which contain dexamethasone-loaded PLGA microspheres. Figure 4 confirms the presence of microspheres and the distribution of HA inside the composite scaffolds. Based on the SEM observation, the unidirectional pores were formed during freeze casting process. This interconnected porous microstructure with approximately $95 \%$ porosity allows for a proper vascularization of the implant, as well as the flow of nutrients and waste products. As previously reported by 
Zamanian et al. [4,31,34,62], SEM micrographs of the vertical cross-section of all the scaffolds (parallel to the direction of solidification) show the presence of the unidirectional channels and lamellar porous morphology, formed along the direction of ice crystals, resulting in an anisotropic microstructure, the average pore size values along the parallel direction (Figure 6) are indicative of the elongation of walls in solidification direction, and the dissimilar values measured along vertical and horizontal directions confirm the anisotropic features of the samples. The concentration of HA and cooling rate have remarkable effects on the microstructure and morphology of the samples. The results illustrated that decreasing the amount of HA leads to crack formation in the walls, due to the low mechanical resistance of gelatin at very low temperatures provided by liquid nitrogen. In this study, composite scaffolds were fabricated using two different cooling rates. The pore size and wall thickness can be adjusted by increasing or decreasing the cooling rate during the freezing process. Figures 3 and 6 reveal that increasing the cooling rate results in the formation of smaller pores and thinner walls. As shown in Figure 6, at fixed amounts of HA, average pore size decreases by increasing the cooling rate. Furthermore, at a constant temperature, the average pore size decreases by increasing the HA content in perpendicular direction and vertical measurements of parallel direction due to preventing the creation of cracks in the walls. However, the elongation of walls decreased by increasing the HA content in the parallel direction. Although 50R1 scaffolds have unidirectional and anisotropic microstructure, they have square pores. This condition changes by decreasing the HA content.

\subsection{Fourier Transform Infrared Spectrum}

FTIR spectroscopy is one of the best methods to determine the chemical groups present in a sample. The infrared beam passes through a sample and makes the bonds stretch, contract, or bend. The absorption of the radiation and the resultant vibration modes occur at specific wavenumbers $\left(\mathrm{cm}^{-1}\right)$ [69]. The FTIR spectra of the raw materials, microspheres and scaffolds are shown in Figure 7 (a,b). In the case of HA, the O-H stretching bond is observed at 3555 $\mathrm{cm}^{-1}$. $\mathrm{CO}_{3}^{-2}$ peak around $1600 \mathrm{~cm}^{-1}$ is detected, confirming the presence of carbonate apatite. Additionally, the peak at $976.89 \mathrm{~cm}^{-1}$ corresponds to the symmetric stretching mode of $\mathrm{PO}_{4}{ }^{3-}$.

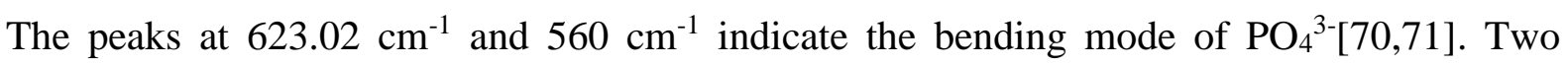
absorption peaks appearing at $1650 \mathrm{~cm}^{-1}$ and $1540 \mathrm{~cm}^{-1}$, correspond to amide I band and II band of gelatin, respectively [72]. The peaks corresponding to $\mathrm{C}=\mathrm{O}$ stretch in 
dexamethasone, are observed at approximately $1660 \mathrm{~cm}^{-1}$ in the case of drug-containing microspheres [73].

For pure PLGA, the strong characteristic absorption band at about $1752 \mathrm{~cm}^{-1}$ can be attributed to the stretching vibration of $\mathrm{C}-\mathrm{O}$, the signal at $1182 \mathrm{~cm}^{-1}$ might be assigned to the C-O-C ether group stretching vibration. The peaks at $1130 \mathrm{~cm}^{-1}$ and $1452 \mathrm{~cm}^{-1}$ arise from C$\mathrm{O}$ bond and methyl group $\mathrm{C}-\mathrm{H}$ bond of PLGA, respectively [72]. These characteristic absorption bands are also observed in the FTIR spectra of composite scaffolds. Additionally, a strong peak at $1450 \mathrm{~cm}^{-1}$ is observed in the cross-linked gelatin. Additional peaks are observed at $1470-1570 \mathrm{~cm}^{-1}$, which intensify as the cross-linking reaction proceeds [74].

\subsection{Phase Analysis}

The X-ray patterns of scaffolds show the major HA peaks at $2 \theta$ angles of $26,31.8,39.8$, 46.7, 53.3 degrees (Figure 8), which are indexed using JCPDS\#76-0694 (HA) [54]. The purity of HA was confirmed by the absence of a secondary phase $[3,4,75]$. The increased intensity of specific peaks in the case of higher HA contents is quite reasonable.

\subsection{Mechanical Behavior}

Ideally, the tissue engineering scaffolds should supply mechanical properties according to the anatomical site of defect, and keep their stability during implantation. Producing scaffolds with adequate mechanical properties is one of the great challenges of tissue engineering. Therefore, the implanted scaffold must have sufficient mechanical integrity during tissue formation and completion of remodeling process [66]. Figure 9 compares the strength values of HA-gelatin scaffolds, fabricated by freeze casting technique. Based on the obtained results, mechanical strength of 15R1, 30R1, 50R1, 15R4, 30R4 and 50R4 were approximately 1.72, $1.91,2.22,1.98,2.18$ and 2.45, respectively. As a consequence, in both cooling rates mechanical strength of scaffolds increased as a result of the increase in the HA content. The larger temperature gradients, created by an increase in the freezing rate, resulted in smaller pore sizes, and a consequent increase in the strength of the bodies. Faster freezing rates thicken the crystal walls and therefore result in increased mechanical strength values [4]. Although gelatin has adverse effects on the mechanical behavior of the scaffolds, it plays an important role in increasing the wettability of the scaffolds and promoting the cellular response. [72]. 


\subsection{Differential Scanning Calorimetry}

Figure 10 demonstrates the results of composite scaffolds before and after immersion in SBF and apatite-like layer formation. Due to the presence of HA in the pure samples, the intensity of some specific peaks changed by apatite formation. As shown in Figure 10, decomposition temperature starts at $50{ }^{\circ} \mathrm{C}$ [76]. Endothermic peaks at $100{ }^{\circ} \mathrm{C}$ correspond to water loss associated with hydrophilic groups [77]. At $250{ }^{\circ} \mathrm{C}$ the desorption of water molecules is observed [78]. Glass transition of polymer occurs at $290{ }^{\circ} \mathrm{C}$ and thermal decomposition of amino groups in gelatin happens at $317{ }^{\circ} \mathrm{C}$ [79]. Furthermore, the exothermic peak at $400{ }^{\circ} \mathrm{C}$ can be attributed to the crystallization of HA. The phase transformation of $\mathrm{HA}$ is observed at $560{ }^{\circ} \mathrm{C}$ [78]. This sharp peak appeares after immersion in SBF solution and apatite formation.

\subsection{Swelling Ratio}

Swelling ratio plays an undeniable role in supporting cellular process such as penetration of nutrients and excretion of waste products. The water uptake ability of the freeze-cast scaffolds after 24 hours of incubation in PBS was 1733, 1609, 1500, 1422, 1207 and 1111 for scaffolds 15R1, 30R1, 50R1, 15R4, 30R4 and 50R4, respectively. Figure 11 shows the swelling ratios as a function of time of various scaffolds. The swelling ratios increased within the initial 3 hours, and then slightly increased until the end of the test. Lower HA contents resulted in an increased PBS absorption of composite scaffolds. Higher amounts of gelatin improve wettability of the structure and affect the absorption behavior. This might be attributed to the presence of amine and carboxylic functional groups in the gelatin structure [72]. Smaller pores with thick walls which were created by higher freezing gradients decreased the water uptake ability. The fast initial swelling is mainly caused by the porous structure of the scaffolds which allows PBS solution to infiltrate inside the scaffolds rapidly. The followed steady swelling is probably attributed to the water binding of gelatin [15].

\subsection{Hydrolytic Biodegradation}

The scaffold apparently serves as an active natural extracellular matrix and allows cells to attach, migrate, proliferate and differentiate [35]. Nonetheless, these constructs are not permanent and should be replaced by actual extracellular matrix, created by cellular activity. Therefore, the biodegradable behavior of scaffolds is of great importance, because it allows for the formation of the new ECM in which cells can secrete their products and regenerate damages [66]. Ideally, the rate of degradation should mirror the rate of tissue formation [35]. 
Figure 12 shows the biodegradation of scaffolds as a function of incubation time in PBS at 37 ${ }^{\circ} \mathrm{C}$ after 4 weeks. The results of mass loss rate demonstrated that lower freezing gradient increases hydrolytic degradation capability in comparison with higher ones due to the increase in the swelling ratio. Although higher cooling rates decrease the PBS absorption and the rate of biodegradation, they result in an increased mechanical strength capable of preventing the sudden collapse of the structure. Nonetheless, the amount of HA in constructs affects the biodegradation rate. The results illustrated that at a constant freezing gradient, the rate of hydrolytic biodegradation decreased as a result of an increase in the HA content. Peter investigated this phenomena in the degradation of chitosan-gelatin-nanohydroxyapatite composite scaffolds [80]. Since gelatin contains amide and carboxyl functional groups, it shows hydrophilic behavior and a quick hydrolysis of its chains during interaction with water molecules [74]. In this study, the quick hydrolysis was controlled the by cross linking reaction of glutaraldehyade. The degradation mechanism of PLGA microspheres affects the drug release behavior and should be considered. Owing to the aliphatic nature of PLGA, these polymeric microspheres play an important role in the hydrolytic mechanism [81]. Lactic acid and glycolic acid are the two main products of PLGA biodegradation and excrete as $\mathrm{H}_{2} \mathrm{O}$ and $\mathrm{CO}_{2}$ [82]. Anderson et al. demonstrated that the biodegradation rate of PLGA microspheres was affected by the size distribution of microspheres. Since the size distribution of dexamethasone-loaded PLGA microspheres is less than $300 \mathrm{~nm}$, homogeneous biodegradation occurs and an equivalent rate of degradation in bulk and surface is expected [81].

\subsection{Bioactivity Analysis}

The X-ray patterns of composite scaffolds show the increased intensity of the major HA peaks at $2 \theta$ angles of 26, 31.8, 39.8, 46.7, 53.3 degrees (Figure 13), which are indexed using JCPDS\#76-0694 (HA) [54]. The increase in the intensity of specific peaks observed in the patterns of the samples after being in SBF solution for 7 days in comparison with the initial patterns demonstrated that raw materials can support bioactive behavior of scaffolds, as stated in other studies $[83,84]$. Moreover, based on this observation, higher amounts of HA support more apatite formation. The results of SEM-EDX of the samples (Figure 14) after immersion in SBF solution for 14 days reveal higher weight ratios of $\mathrm{Ca} / \mathrm{P}$ as a result of an increase in the HA content. Also, at lower cooling rates, due to the higher levels of HA sedimentation, an increased $\mathrm{Ca} / \mathrm{P}$ ratio is obtained. The results of DSC analysis indicated the formation of a new apatite layer after immersing in SBF, confirming the ability of scaffolds 
to support bioactivity. Nonetheless, the role of dexamethasone and a sustained drug release level in stimulating the absorption of $\mathrm{Ca}$ and $\mathrm{P}$ should not be ignored. According to Duarte et al., dexamethasone enhances the differentiation of bone marrow stem cells to osteoblastic cells and expression of osteogenic markers [85].

\subsection{Dexamethasone Release Behavior}

Nowadays, investigators employ various technologies to construct interconnected porous scaffolds to regenerate the tissues and to control and target the release of biological and pharmaceutical agents in tissue engineering applications. Scaffolds incorporated with controlled-release systems require large pores to enable the diffusion of the drug. Biological and pharmaceutical agents such as drugs, growth factors, and genes can be directly mixed into the polymer solution to prepare drug carriers with controlled-release properties [86]. Figure 15 depicts the cumulative release level of the dexamethasone-loaded PLGA microspheres, as a part of the composite structure, as a function of incubation time in PBS at $37{ }^{\circ} \mathrm{C}$ during 21 days.

The results demonstrated that increasing water absorption and biodegradation rate can influence the release behavior. As a consequence, at lower freezing gradients, increasing these parameters enhances the release rate. However, the role of the HA content in scaffolds should not be ignored. Reducing the amount of HA increased the HA-gelatin ratio. Therefore, at lower HA amounts, the hydrophilic functional groups of gelatin play a more active role in improving the release ratio. The degradation process of PLGA, as a semicrystalline polymer, begins at the amorphous domains and then extends to the crystalline regions. Therefore, a fast release rate is observed during the initial stages because of the quick degradation of the amorphous sections. The slower degradation of the crystalline regions decreases the rate of drug release [81]. The release diagram of all the groups indicates that the rate of release increases moderately during the initial 5 days of the test, then rises suddenly until day 7 and follows a steady increase. Hence, it could be concluded that swelling of the scaffolds affects the dexamethasone release during all 21 days. However, the degradation process and collapse of the pore walls play an undeniable role in increasing the release level between days 5 and 7 .

\section{Conclusion}

In this study, HA-gelatin scaffolds, containing dexamethasone-loaded PLGA microspheres, were synthesized by freeze casting technique. The composite scaffolds have unidirectional and lamellar type microstructures and porous interconnected morphology. The 
average size of pores was reduced by increasing the cooling rate. Although lower freezing gradients have an adverse effect on the mechanical properties, they result in increased swelling ratios, biodegradation rates and release levels. The role of $\mathrm{HA}$ on the physicochemical properties should not be ignored. Increasing the HA content improves the mechanical strength, but results in lower swelling ratios, biodegradation rates and release levels by affecting the HA-gelatin ratio and diminishing the role of gelatin. Furthermore, these constructs can serve as bioactive structures for supporting the neo-formation of damaged tissue. Based on the obtained results, the HA-gelatin scaffolds have the necessary features to regenerate defects especially at lower freezing gradients and higher amounts of HA and serve as a basis for future cellular studies to evaluate the effect of these drug-release constructs on cellular differentiation and expression of osteogenic markers.

\section{Acknowledgment}

This research was funded by the Iran National Science Foundation (presidency of Islamic republic of Iran, vice-presidency for science and technology).

\section{References}

[1] B. Guo, L. Glavas, A.-C. Albertsson, Biodegradable and electrically conducting polymers for biomedical applications, Prog. Polym. Sci. 38 (2013) 1263-1286. doi:10.1016/j.progpolymsci.2013.06.003.

[2] S.-T. Yang, Perspectives on carbon nanotube-based scaffolds in nerve tissue engineering, J. Tissue Sci. Eng. 03 (2012) 1-2. doi:10.4172/2157-7552.1000e108.

[3] S. Farhangdoust, A. Zamanian, M. Yasaei, M. Khorami, The effect of processing parameters and solid concentration on the mechanical and microstructural properties of freeze-casted macroporous hydroxyapatite scaffolds., Mater. Sci. Eng. C. Mater. Biol. Appl. 33 (2013) 453-60. doi:10.1016/j.msec.2012.09.013.

[4] A. Zamanian, S. Farhangdoust, M. Yasaei, M. Khorami, M. Hafezi, The effect of particle size on the mechanical and microstructural properties of freeze-casted macroporous hydroxyapatite scaffolds, Int. J. Appl. Ceram. Technol. 11 (2014) 12-21. doi:10.1111/ijac.12031.

[5] M. Hafezi, N. Nezafati, A. Nadernezhad, M. Yasaei, A. Zamanian, S. Mobini, Effect of sintering temperature and cooling rate on the morphology, mechanical behavior and 
apatite-forming ability of a novel nanostructured magnesium calcium silicate scaffold prepared by a freeze casting method, J. Mater. Sci. 49 (2014) 1297-1305. doi:10.1007/s10853-013-7813-8.

[6] N. Arabi, A. Zamanian, Effect of cooling rate and gelatin concentration on the microstructural and mechanical properties of ice template gelatin scaffolds., Biotechnol. Appl. Biochem. 60 (2013) 573-9. doi:10.1002/bab.1120.

[7] S. Deville, E. Saiz, A.P. Tomsia, Freeze casting of hydroxyapatite scaffolds for bone $\begin{array}{lllll}\text { tissue } & \text { engineering., } & \text { Biomaterials. } & 27 & \text { (2006) }\end{array}$ doi:10.1016/j.biomaterials.2006.06.028.

[8] S. Izadi, S. Hesaraki, M. Hafezi-Ardakani, Evaluation nanostructure properties of bioactive glass scaffolds for bone tissue engineering, Adv. Mater. Res. 829 (2013) 289-293. doi:10.4028/www.scientific.net/AMR.829.289.

[9] S. Bhat, A. Kumar, Cell proliferation on three-dimensional chitosan-agarose-gelatin cryogel scaffolds for tissue engineering applications., J. Biosci. Bioeng. 114 (2012) 663-70. doi:10.1016/j.jbiosc.2012.07.005.

[10] H. TAN, J. WU, L. LAO, C. GAO, Gelatin/chitosan/hyaluronan scaffold integrated with PLGA microspheres for cartilage tissue engineering, Acta Biomater. 5 (2009) 328-337. doi:10.1016/j.actbio.2008.07.030.

[11] Y.-C. Kuo, C.-F. Yeh, J.-T. Yang, Differentiation of bone marrow stromal cells in poly(lactide-co-glycolide)/chitosan scaffolds., Biomaterials. 30 (2009) 6604-13. doi:10.1016/j.biomaterials.2009.08.028.

[12] M. Sarem, F. Moztarzadeh, M. Mozafari, V.P. Shastri, Optimization strategies on the structural modeling of gelatin/chitosan scaffolds to mimic human meniscus tissue., Mater. Sci. Eng. C. Mater. Biol. Appl. 33 (2013) 4777-85. doi:10.1016/j.msec.2013.07.036.

[13] J. Han, P. Lazarovici, C. Pomerantz, X. Chen, Y. Wei, P.I. Lelkes, Co-electrospun blends of PLGA, gelatin, and elastin as potential nonthrombogenic scaffolds for vascular tissue engineering., Biomacromolecules. $12 \quad$ (2011) 399-408. doi:10.1021/bm101149r.

[14] M. Shachar, O. Tsur-Gang, T. Dvir, J. Leor, S. Cohen, The effect of immobilized RGD peptide in alginate scaffolds on cardiac tissue engineering., Acta Biomater. 7 (2011) 
152-62. doi:10.1016/j.actbio.2010.07.034.

[15] F. Zhang, C. He, L. Cao, W. Feng, H. Wang, X. Mo, et al., Fabrication of gelatinhyaluronic acid hybrid scaffolds with tunable porous structures for soft tissue engineering., Int. J. Biol. Macromol. $48 \quad$ (2011) 474-81. doi:10.1016/j.ijbiomac.2011.01.012.

[16] L. Ghasemi-Mobarakeh, M.P. Prabhakaran, M. Morshed, M.-H. Nasr-Esfahani, S. Ramakrishna, Electrospun poly(epsilon-caprolactone)/gelatin nanofibrous scaffolds for nerve tissue engineering., Biomaterials. $29 \quad$ (2008) 4532-9. doi:10.1016/j.biomaterials.2008.08.007.

[17] X. Wu, Y. Liu, X. Li, P. Wen, Y. Zhang, Y. Long, et al., Preparation of aligned porous gelatin scaffolds by unidirectional freeze-drying method., Acta Biomater. 6 (2010) 1167-77. doi:10.1016/j.actbio.2009.08.041.

[18] A. Zamanian, F. Ghorbani, H. Nojehdehian, Morphological comparison of PLGA/Gelatin scaffolds produced by freeze casting and freeze drying methods, Appl. Mech. Mater. 467 (2013) 108-111. doi:10.4028/www.scientific.net/AMM.467.108.

[19] F. Ghorbani, H. Nojehdehyan, A. Zamanian, M. Gholipourmalekabadi, M. Mozafari, Synthesis, physico-chemical characteristics and cellular behavior of poly(lactic-coglycolic acid)/gelatin nanofibrous scaffolds for engineering soft connective tissues, Adv. Mater. Lett. 7 (2016) 163-169. doi:10.5185/amlett.2016.6003.

[20] X. Niu, Q. Feng, M. Wang, X. Guo, Q. Zheng, Porous nano-HA/collagen/PLLA scaffold containing chitosan microspheres for controlled delivery of synthetic peptide derived from BMP-2, J. Control. Release. 134 (2009) 111-117. doi:10.1016/j.jconrel.2008.11.020.

[21] V. Thomas, D.R. Dean, M. V Jose, B. Mathew, S. Chowdhury, Y.K. Vohra, Nanostructured biocomposite scaffolds based on collagen coelectrospun with nanohydroxyapatite., Biomacromolecules. 8 (2007) 631-7. doi:10.1021/bm060879w.

[22] G. Chen, J. Chen, B. Yang, L. Li, X. Luo, X. Zhang, et al., Combination of aligned PLGA/Gelatin electrospun sheets, native dental pulp extracellular matrix and treated dentin matrix as substrates for tooth root regeneration, Biomaterials. 52 (2015) 56-70. doi:10.1016/j.biomaterials.2015.02.011.

[23] A. Brown, S. Zaky, H. Ray, C. Sfeir, Porous magnesium/PLGA composite scaffolds 
for enhanced bone regeneration following tooth extraction, Acta Biomater. 11 (2015) 543-553. doi:10.1016/j.actbio.2014.09.008.

[24] P. Denis, J. Dulnik, P. Sajkiewicz, Electrospinning and structure of bicomponent polycaprolactone/gelatin nanofibers obtained using alternative solvent system, Int. J. Polym. Mater. Polym. Biomater. $64 \quad$ (2014) 354-364. doi:10.1080/00914037.2014.945208.

[25] K.E. Uhrich, D. Abdelhamid, Biosynthetic polymers for medical applications, Elsevier, 2016. doi:10.1016/B978-1-78242-105-4.00003-1.

[26] F. Wang, J. Finnin, C. Tait, S. Quirk, I. Chekhtman, A.C. Donohue, et al., The hydrolysis of diclofenac esters: synthetic prodrug building blocks for biodegradable drug-polymer conjugates., J. Pharm. Sci. 105 (2015) 773-785. doi:10.1002/jps.24665.

[27] A. Rogina, Electrospinning process: Versatile preparation method for biodegradable and natural polymers and biocomposite systems applied in tissue engineering and drug delivery, Appl. Surf. Sci. 296 (2014) 221-230. doi:10.1016/j.apsusc.2014.01.098.

[28] K. Shah, Development of gelatin microbubble based, University of Texas at Arlingtopn, 2012.

[29] S. Dorozhkin, Calcium orthophosphate-based bioceramics, Materials (Basel). 6 (2013) 3840-3942. doi:10.3390/ma6093840.

[30] J.S. Al-Sanabani, A.A. Madfa, F.A. Al-Sanabani, Application of calcium phosphate materials in dentistry, Int. J. Biomater. 2013 (2013) 1-12. doi:10.1155/2013/876132.

[31] S.M.H. Ghazanfari, A. Zamanian, Phase transformation, microstructural and mechanical properties of hydroxyapatite/alumina nanocomposite scaffolds produced by freeze casting, Ceram. Int. $39 \quad$ (2013) 9835-9844. doi:10.1016/j.ceramint.2013.05.096.

[32] M. Pourhaghgouy, A. Zamanian, Ice-templated scaffolds of bioglass nanoparticles reinforced-chitosan, in: 2014 21th Iran. Conf. Biomed. Eng., IEEE, 2014: pp. 48-52. doi:10.1109/ICBME.2014.7043892.

[33] M. Pourhaghgouy, A. Zamanian, M. Shahrezaee, M.P. Masouleh, Physicochemical properties and bioactivity of freeze-cast chitosan nanocomposite scaffolds reinforced with bioactive glass, Mater. Sci. Eng. C. 58 (2016) 180-186. 
doi:10.1016/j.msec.2015.07.065.

[34] A. Zamanian, S. Farhangdoust, M. Yasaei, M. Khorami, M. Abbasabadi, The effect of sintering temperature on the microstructural and mechanical characteristics of hydroxyapatite macroporous scaffolds prepared via freeze-casting, Key Eng. Mater. 529-530 (2012) 133-137. doi:10.4028/www.scientific.net/KEM.529-530.133.

[35] M. Alizadeh, F. Abbasi, a B. Khoshfetrat, H. Ghaleh, Microstructure and characteristic properties of gelatin/chitosan scaffold prepared by a combined freezedrying/leaching method., Mater. Sci. Eng. C. Mater. Biol. Appl. 33 (2013) 3958-67. doi:10.1016/j.msec.2013.05.039.

[36] H. Ghaleh, F. Abbasi, M. Alizadeh, A.B. Khoshfetrat, Mimicking the quasi-random assembly of protein fibers in the dermis by freeze-drying method., Mater. Sci. Eng. C. Mater. Biol. Appl. 49 (2015) 807-15. doi:10.1016/j.msec.2015.01.071.

[37] S. Kidoaki, I.K. Kwon, T. Matsuda, Mesoscopic spatial designs of nano- and microfiber meshes for tissue-engineering matrix and scaffold based on newly devised multilayering and mixing electrospinning techniques., Biomaterials. 26 (2005) 37-46. doi:10.1016/j.biomaterials.2004.01.063.

[38] B.S. Jha, R.J. Colello, J.R. Bowman, S. a Sell, K.D. Lee, J.W. Bigbee, et al., Two pole air gap electrospinning: Fabrication of highly aligned, three-dimensional scaffolds for nerve reconstruction., Acta Biomater. 7 (2011) 203-15. doi:10.1016/j.actbio.2010.08.004.

[39] D. Gupta, J. Venugopal, S. Mitra, V.R. Giri Dev, S. Ramakrishna, Nanostructured biocomposite substrates by electrospinning and electrospraying for the mineralization of osteoblasts., $\quad$ Biomaterials. $\quad 30 \quad$ (2009) 2085-94. doi:10.1016/j.biomaterials.2008.12.079.

[40] X. Geng, O.-H. Kwon, J. Jang, Electrospinning of chitosan dissolved in concentrated acetic acid solution., Biomaterials. $26 \quad$ (2005) 5427-32. doi:10.1016/j.biomaterials.2005.01.066.

[41] Q.P. Pham, U. Sharma, A.G. Mikos, Electrospinning of polymeric nanofibers for tissue engineering applications: a review., Tissue Eng. 12 (2006) 1197-211. doi:10.1089/ten.2006.12.1197.

[42] J.J. Yoon, J.H. Kim, T.G. Park, Dexamethasone-releasing biodegradable polymer 
scaffolds fabricated by a gas-foaming/salt-leaching method, Biomaterials. 24 (2003) 2323-2329. doi:10.1016/S0142-9612(03)00024-3.

[43] a S. Rowlands, S. a Lim, D. Martin, J.J. Cooper-White, Polyurethane/poly(lactic-coglycolic) acid composite scaffolds fabricated by thermally induced phase separation., Biomaterials. 28 (2007) 2109-21. doi:10.1016/j.biomaterials.2006.12.032.

[44] X. Liu, P.X. Ma, Phase separation, pore structure, and properties of nanofibrous $\begin{array}{lllll}\text { gelatin } & \text { scaffolds, } & \text { Biomaterials. } & 30 & \text { (2009) 4094-4103. }\end{array}$ doi:10.1016/j.biomaterials.2009.04.024.

[45] A. Asefnejad, M.T. Khorasani, A. Behnamghader, B. Farsadzadeh, S. Bonakdar, Manufacturing of biodegradable polyurethane scaffolds based on polycaprolactone using a phase separation method: physical properties and in vitro assay., Int. J. Nanomedicine. 6 (2011) 2375-84. doi:10.2147/IJN.S15586.

[46] S. Deville, Freeze-casting of porous biomaterials: structure, properties and opportunities, Materials (Basel). 3 (2010) 1913-1927. doi:10.3390/ma3031913.

[47] R.S. Tığlı, M. Gümüşderelioğlu, Dexamethasone releasing chitosan scaffold for cartilage development, Eur. Cells Mater. 12 (2006) 73.

[48] A. Martins, A.R.C. Duarte, S. Faria, A.P. Marques, R.L. Reis, N.M. Neves, Osteogenic induction of hBMSCs by electrospun scaffolds with dexamethasone release functionality, $\quad$ Biomaterials. $\quad 31 \quad$ (2010) 5875-5885. doi:10.1016/j.biomaterials.2010.04.010.

[49] J.S. Son, S.G. Kim, J.S. Oh, M. Appleford, S. Oh, J.L. Ong, et al., Hydroxyapatite/polylactide biphasic combination scaffold loaded with dexamethasone for bone regeneration, J. Biomed. Mater. Res. - Part A. 99 A (2011) 638-647. doi:10.1002/jbm.a.33223.

[50] S. Das, U. Subuddhi, Controlled delivery of dexamethasone to the intestine from poly(vinyl alcohol)-poly(acrylic acid) microspheres containing drug-cyclodextrin complexes: influence of method of preparation of inclusion complex, RSC Adv. 4 (2014) 24222. doi:10.1039/c4ra02736a.

[51] J.S. Son, M. Appleford, J.L. Ong, J.C. Wenke, J.M. Kim, S.H. Choi, et al., Porous hydroxyapatite scaffold with three-dimensional localized drug delivery system using biodegradable microspheres, J. Control. Release. 153 (2011) 133-140. 
doi:10.1016/j.jconrel.2011.03.010.

[52] T. Hickey, D. Kreutzer, D.J. Burgess, F. Moussy, Dexamethasone/PLGA microspheres for continuous delivery of an anti-inflammatory drug for implantable medical devices, Biomaterials. 23 (2002) 1649-1656. doi:10.1016/S0142-9612(01)00291-5.

[53] H. Nojehdehian, F. Moztarzadeh, H. Baharvand, H. Nazarian, M. Tahriri, Preparation and surface characterization of poly-1-lysine-coated PLGA microsphere scaffolds containing retinoic acid for nerve tissue engineering: In vitro study, Colloids Surfaces B Biointerfaces. 73 (2009) 23-29. doi:10.1016/j.colsurfb.2009.04.029.

[54] J. LI, Y. CHEN, Y. YIN, F. YAO, K. YAO, Modulation of nano-hydroxyapatite size via formation on chitosan-gelatin network film in situ, Biomaterials. 28 (2007) 781790. doi:10.1016/j.biomaterials.2006.09.042.

[55] L. Ghasemi-Mobarakeh, D. Semnani, M. Morshed, A novel method for porosity measurement of various surface layers of nanofibers mat using image analysis for tissue engineering applications, J. Appl. Polym. Sci. 106 (2007) 2536-2542. doi:10.1002/app.26949.

[56] C.M. Vaz, S. van Tuijl, C.V.C. Bouten, F.P.T. Baaijens, Design of scaffolds for blood vessel tissue engineering using a multi-layering electrospinning technique., Acta Biomater. 1 (2005) 575-82. doi:10.1016/j.actbio.2005.06.006.

[57] M. Mozafari, Moztarzadeh, Jalali, N. Alhosseini, Asgari, Dodel, et al., Synthesis and characterization of electrospun polyvinyl alcohol nanofibrous scaffolds modified by blending with chitosan for neural tissue engineering, Int. J. Nanomedicine. (2012) 25. doi:10.2147/IJN.S25376.

[58] V.K. Nandagiri, P. Gentile, V. Chiono, C. Tonda-Turo, A. Matsiko, Z. Ramtoola, et al., Incorporation of PLGA nanoparticles into porous chitosan-gelatin scaffolds: influence on the physical properties and cell behavior., J. Mech. Behav. Biomed. Mater. 4 (2011) 1318-27. doi:10.1016/j.jmbbm.2011.04.019.

[59] J. Khazaei, Water Absorption Characteristics, Cercet. Agron. Mold. XLI (2008) 5-16.

[60] X.-K. Li, S.-X. Cai, B. Liu, Z.-L. Xu, X.-Z. Dai, K.-W. Ma, et al., Characteristics of PLGA-gelatin complex as potential artificial nerve scaffold., Colloids Surf. B. Biointerfaces. 57 (2007) 198-203. doi:10.1016/j.colsurfb.2007.02.010. 
[61] T. Kokubo, H. Takadama, How useful is SBF in predicting in vivo bone bioactivity?, Biomaterials. 27 (2006) 2907-2915. doi:10.1016/j.biomaterials.2006.01.017.

[62] N. Nezafati, M. Hafezi, A. Zamanian, M. Naserirad, Effect of adding nano-titanium dioxide on the microstructure, mechanical properties and in vitro bioactivity of a freeze cast merwinite scaffold, Biotechnol. Prog. 31 (2015) 550-556. doi:10.1002/btpr.2042.

[63] Z.X. Meng, X.X. Xu, W. Zheng, H.M. Zhou, L. Li, Y.F. Zheng, et al., Preparation and characterization of electrospun PLGA/gelatin nanofibers as a potential drug delivery system., Colloids Surf. $\quad$ B. Biointerfaces. $84 \quad$ (2011) 97-102. doi:10.1016/j.colsurfb.2010.12.022.

[64] L. Montenegro, A.M. Panico, A. Ventimiglia, F.P. Bonina, In vitro retinoic acid release and skin permeation from different liposome formulations, Int. J. Pharm. 133 (1996) 89-96. doi:10.1016/0378-5173(95)04422-1.

[65] Guy B. Marin, Advances in Chemical Engineering: Multiscale Analysis, 2016.

[66] F.J. O’Brien, Biomaterials \& scaffolds for tissue engineering, Mater. Today. 14 (2011) 88-95. doi:10.1016/S1369-7021(11)70058-X.

[67] I. Banerjee, D. Mishra, T.K. Maiti, PLGA microspheres incorporated gelatin scaffold: microspheres modulate scaffold properties., Int. J. Biomater. 2009 (2009) 143659. doi:10.1155/2009/143659.

[68] K.D. Newman, M.W. McBurney, Poly(D,L lactic-co-glycolic acid) microspheres as biodegradable microcarriers for pluripotent stem cells., Biomaterials. 25 (2004) 576371. doi:10.1016/j.biomaterials.2004.01.027.

[69] A. Solouk, B.G. Cousins, H. Mirzadeh, A.M. Seifalian, Application of plasma surface modification techniques to improve hemocompatibility of vascular grafts: A review, Biotechnol. Appl. Biochem. 58 (2011) 311-327. doi:10.1002/bab.50.

[70] H. Eslami, M. Solati-Hashjin, M. Tahriri, Synthesis and characterization of hydroxyapatite nanocrystals via chemical precipitation technique, J. Pharm. Sci. 4 (2008).

[71] K. Agrawal, G. Singh, D. Puri, S. Prakash, Synthesis and characterization of hydroxyapatite powder by sol-gel method for biomedical application, J. Miner. Mater. 
Charact. Eng. 10 (2011) 727-734. doi:10.4236/jmmce.2011.108057.

[72] Z.X. Meng, Y.S. Wang, C. Ma, W. Zheng, L. Li, Y.F. Zheng, Electrospinning of PLGA/gelatin randomly-oriented and aligned nanofibers as potential scaffold in tissue engineering, Mater. Sci. Eng. C. $30 \quad$ (2010) 1204-1210. doi:10.1016/j.msec.2010.06.018.

[73] G. Stevenson, The controlled release of dexamethasone from polyterthiophene-based conducting polymers, university of wollonong, 2010.

[74] T.-H. Nguyen, B.-T. Lee, Fabrication and characterization of cross-linked gelatin electro-spun nano-fibers, J. Biomed. Sci. Eng. 03 (2010) 1117-1124. doi:10.4236/jbise.2010.312145.

[75] B. Torabinejad, J. Mohammadi-Rovshandeh, S.M. Davachi, A. Zamanian, Synthesis and characterization of nanocomposite scaffolds based on triblock copolymer of Llactide, $\varepsilon$-caprolactone and nano-hydroxyapatite for bone tissue engineering., Mater. Sci. Eng. C. Mater. Biol. Appl. 42 (2014) 199-210. doi:10.1016/j.msec.2014.05.003.

[76] M. Sivakumar, K.P. Rao, Preparation, characterization, andin vitro release of gentamicin from coralline hydroxyapatite-alginate composite microspheres, J. Biomed. Mater. Res. 65A (2003) 222-228. doi:10.1002/jbm.a.10495.

[77] G.A. Martínez-Castañón, J.P. Loyola-Rodríguez, N. V. Zavala-Alonso, S.E. Hernández-Martínez, N. Niño-Martínez, G. Ortega-Zarzosa, et al., Preparation and characterization of nanostructured powders of hydroxyapatite, Superf. Y Vacio. 25 (2012) 101-105.

[78] S. Jain, Processing of Hydroxyapatite By Biomimetic Process, 2010.

[79] I.X.C. Brasileiro, S. Negra, Thermal characterization of hydroxyapatite-chitosan composites containing tetracycline, IX Congr. Bras. Análise Térmica E Calorimetria. 66 (2014).

[80] M. Peter, Preparation and characterization of chitosan-gelatin/nanohydroxyapatite composite scaffolds for tissue engineering applications, Carbohydr. Polym. 80 (2010) $687-694$.

[81] J.M. Anderson, M.S. Shive, Biodegradation and biocompatibility of PLA and PLGA microspheres, Adv. Drug Deliv. Rev. $64 \quad$ (2012) 72-82. 
doi:10.1016/j.addr.2012.09.004.

[82] J.B. Park, J.D. Bronzino, Biomaterials : principles and applications, 2002.

[83] J.H. Lee, H.L. Jang, K.M. Lee, H.R. Baek, K. Jin, K.S. Hong, et al., In vitro and in vivo evaluation of the bioactivity of hydroxyapatite-coated polyetheretherketone biocomposites created by cold spray technology, Acta Biomater. 9 (2013) 6177-6187. doi:10.1016/j.actbio.2012.11.030.

[84] F. Langenbach, J. Handschel, Effects of dexamethasone, ascorbic acid and $\beta$ glycerophosphate on the osteogenic differentiation of stem cells in vitro., Stem Cell Res. Ther. 4 (2013) 117. doi:10.1186/scrt328.

[85] A.R.C. Duarte, J.F. Mano, R.L. Reis, Preparation of chitosan scaffolds loaded with dexamethasone for tissue engineering applications using supercritical fluid technology, Eur. Polym. J. 45 (2009) 141-148. doi:10.1016/j.eurpolymj.2008.10.004.

[86] B. Dhandayuthapani, Y. Yoshida, T. Maekawa, D.S. Kumar, Polymeric scaffolds in tissue engineering application: a review, Int. J. Polym. Sci. 2011 (2011) 1-19. doi:10.1155/2011/290602. 


\section{Figures Caption:}

Figure. 1: SEM micrographs of dexamethasone-loaded PLGA microspheres.

Figure. 2: Schematic of cross linking reaction and ice solidification in freeze casting technique.

Figure. 3: SEM micrographs of HA-gelatin scaffolds which contain drug-loaded PLGA microspheres with solidification rate of $1{ }^{\circ} \mathrm{C} / \mathrm{min}$ and $4{ }^{\circ} \mathrm{C} / \mathrm{min}$. (Perpendicular direction of a: 15R1, c: 15R4, e: 30R1, g: 30R4, i: 50R1, k: 50R4. Parallel direction of b: 15R1, d: 15R4, f: 30R1, h: 30R4, j: 50R1, 1: 50R4)

Figure. 4: Dispersion of HA and drug-loaded PLGA microspheres in composite scaffolds (a, b, and c contain 15, 30 and $50 \%$ wt HA, respectively and 4.5\%wt PLGA microsphere)

Figure. 5: Size distribution of PLGA microspheres by image measurement software. PLGA microspheres distributed in range of $1-70 \mu \mathrm{m}$.

Figure. 6: Average pore size of composite freeze cast scaffolds by image measurement software in both parallel and perpendicular directions. Pore size reduced by increasing freezing rate. All the samples have lower pore size in horizontal direction that confirms the oriented microstructure of scaffolds.

Figure. 7: FTIR spectrum of a: raw materials (HA, gelatin, PLGA), b: PLGA microspheres with and without dexamethasone and HA-gelatin scaffolds with dexamethasone loaded PLGA microspheres.

Figure. 8: XRD pattern of HA-gelatin scaffolds with dexamethasone loaded PLGA microspheres.

Figure. 9: Mechanical strength of freeze cast HA-gelatin scaffolds. $\left(\mathrm{p}^{*}=0.03, \mathrm{p}^{* *}=0.02\right)$. Increasing the amount of HA and lower solidification rate enhanced mechanical strength.

Figure 10: DSC of Freeze-Cast Hydroxyapatite-Gelatin Matrix.

Figure. 11: Swelling ratio of freeze cast HA-gelatin scaffolds during 2, 4, 6 and 24 hours. $(0.01<\mathrm{p} \leq 0.05: *$ means statistical differences between groups and $\mathrm{p} \leq 0.01$ : ** means differences between groups are considerable). Lower freezing gradient and HA content demonstrated higher PBS absorption. 
Figure. 12: Hydrolytic biodegradation of freeze-cast. HA-gelatin scaffolds during 4 weeks. (Except groups *, ** and ** there are statistical significant differences between other groups). Increasing HA content and freezing rate decreased hydrolytic biodegradation during 4 weeks.

Figure. 13: XRD Spectrum of freeze cast scaffolds after 7 days immersing in SBF.

Figure. 14: SEM-EDX of freeze cast HA-gelatin scaffolds and formation of apatite layers after 14 days immersing in $\mathrm{SBF}(\mathrm{n}=3)$.

Figure. 15: Release behavior of HA-gelatin scaffolds which contain dexamethasone loaded PLGA microspheres during 3, 7, 10, 14 and 21 days. Both lower amount of HA and solidification rate indicated more release rate in each time point. $(0.01<\mathrm{p} \leq 0.05$ : * indicate statistical differences between groups and $\mathrm{p} \leq 0.01$ : ** mean differences between groups are considerable). 

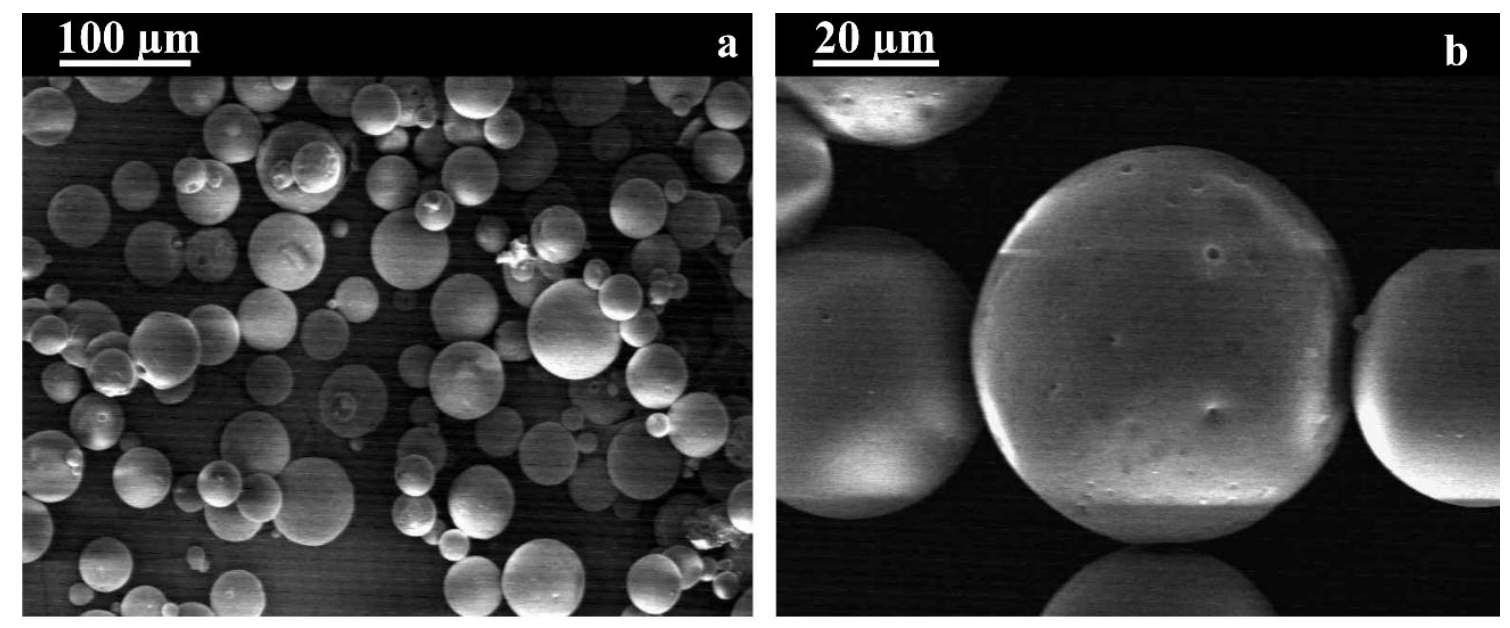

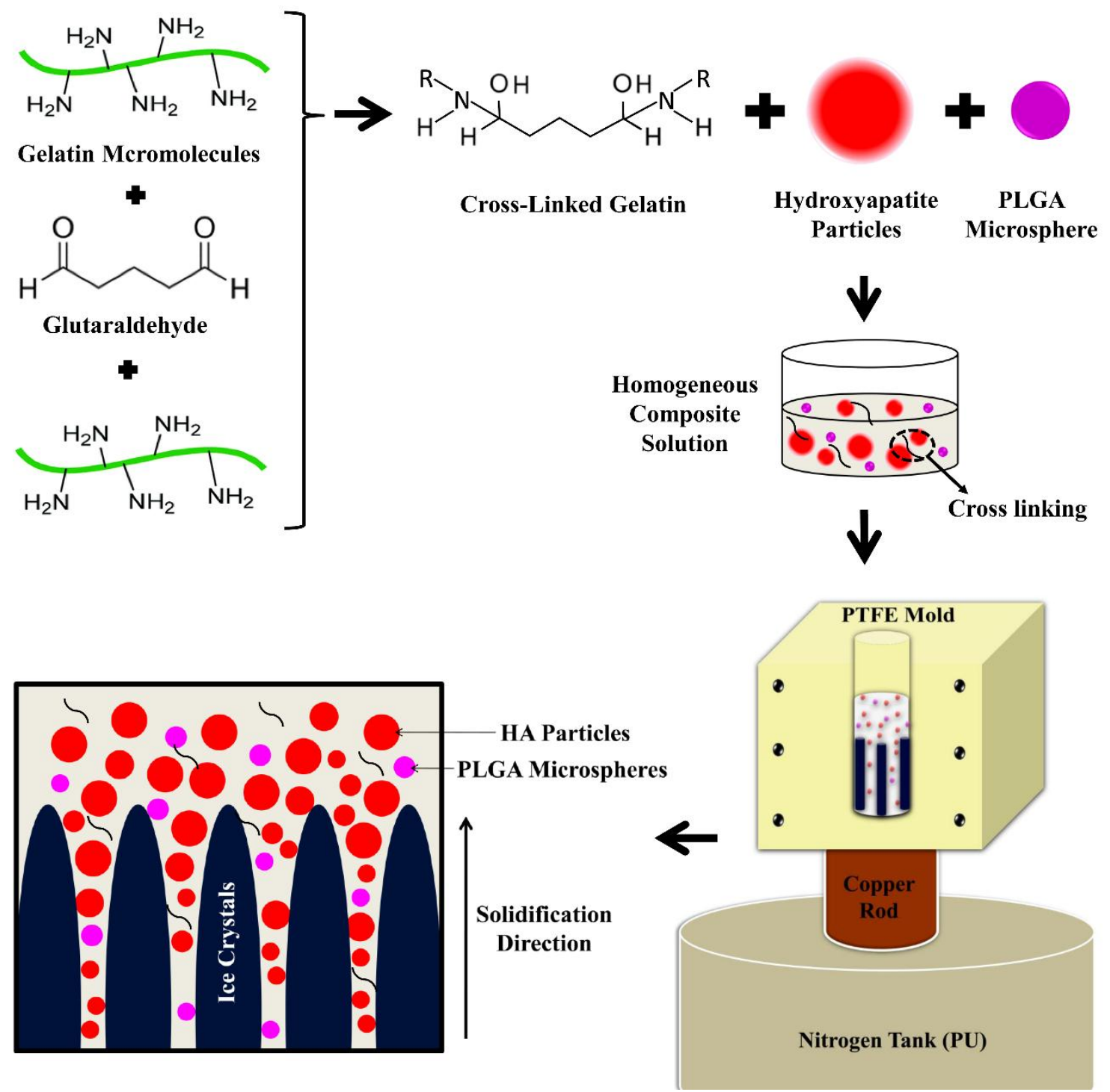


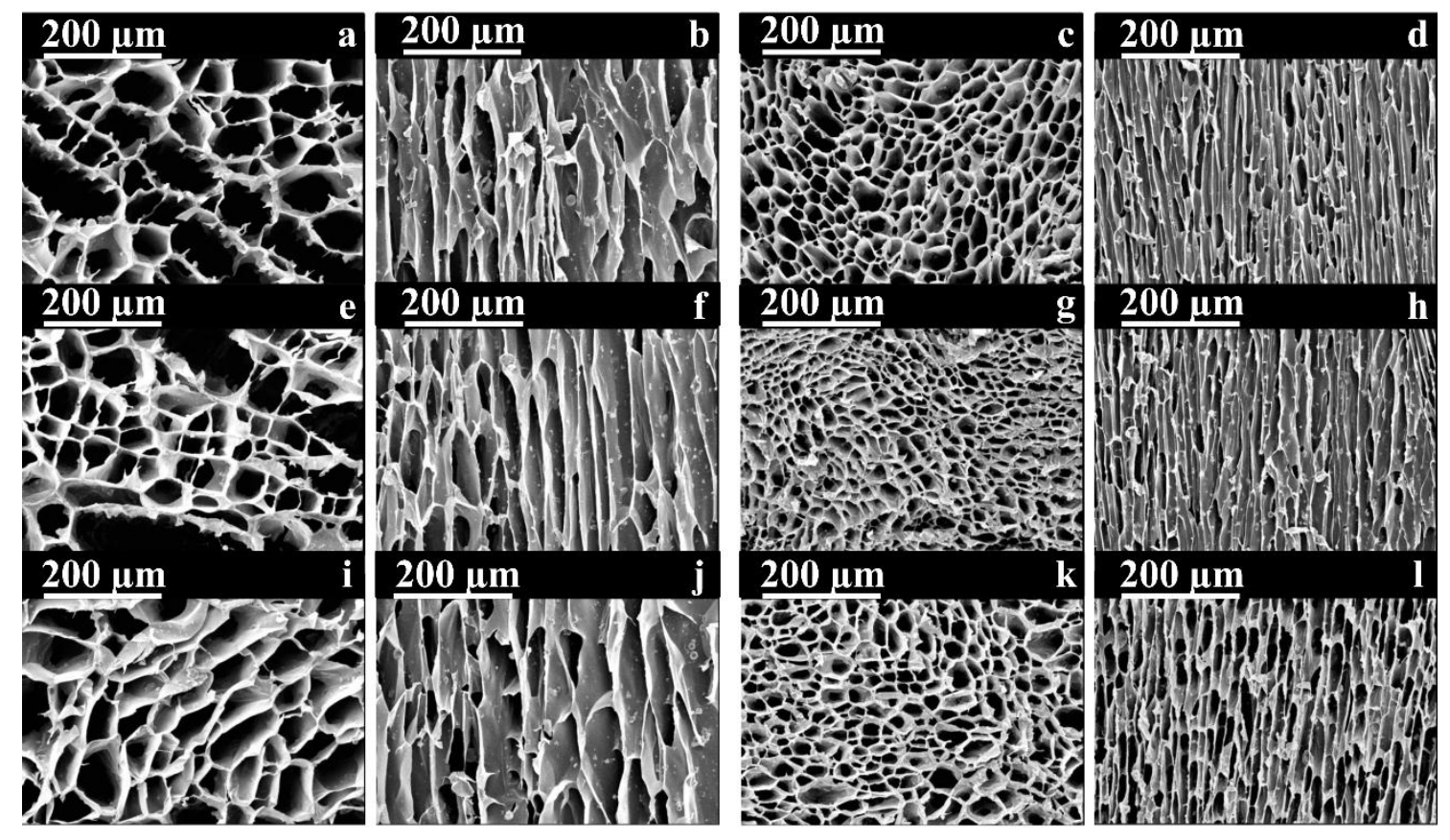




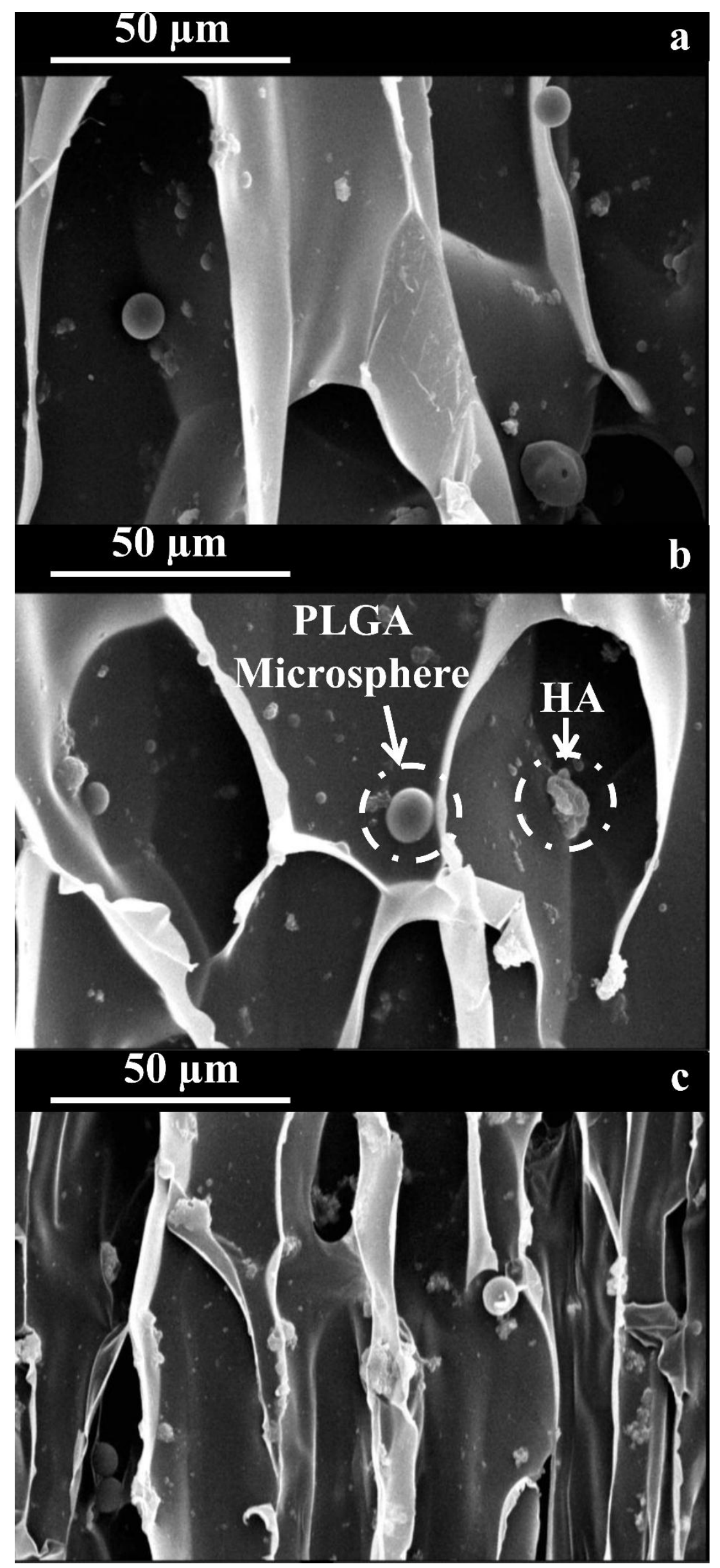




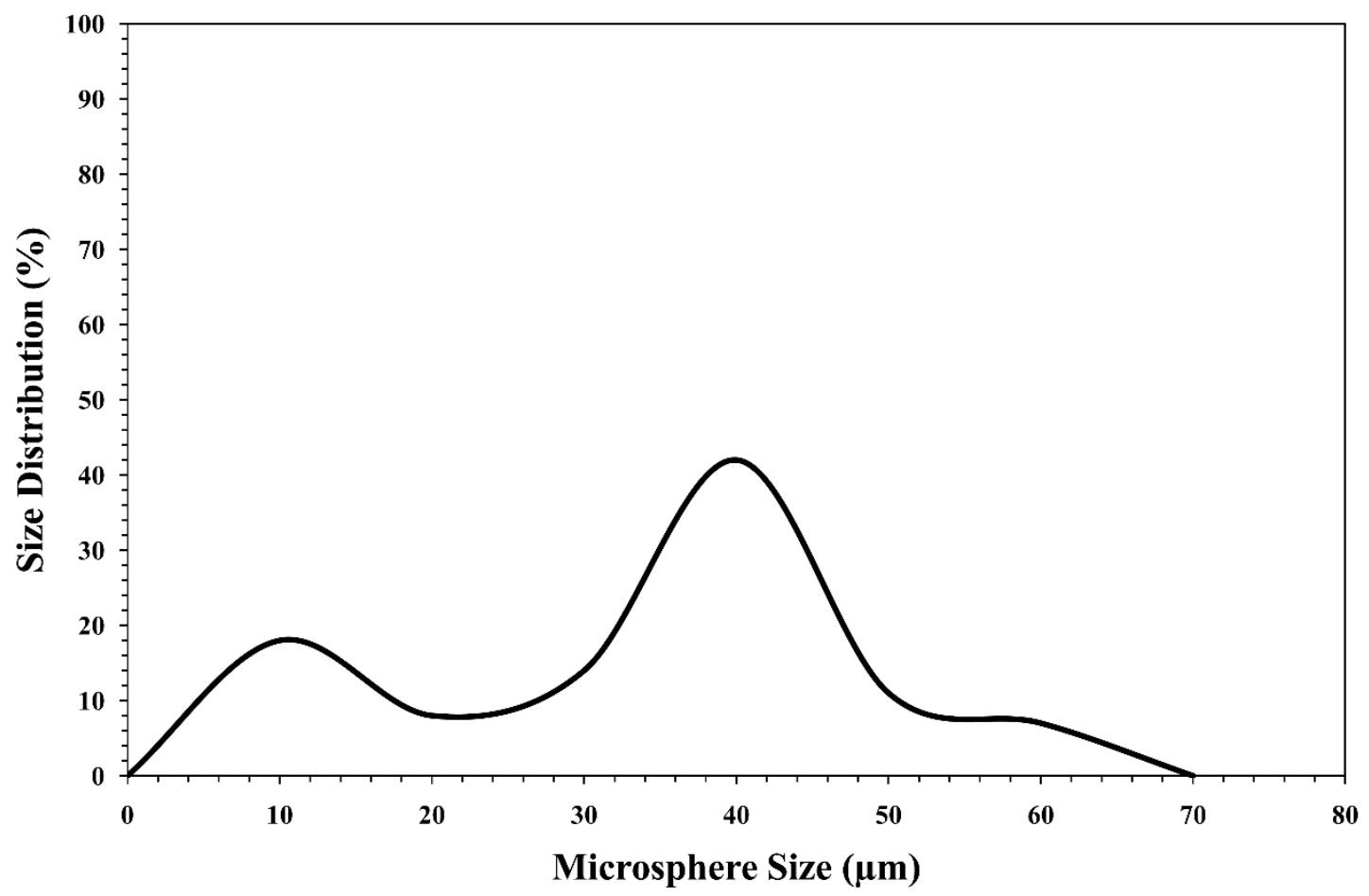




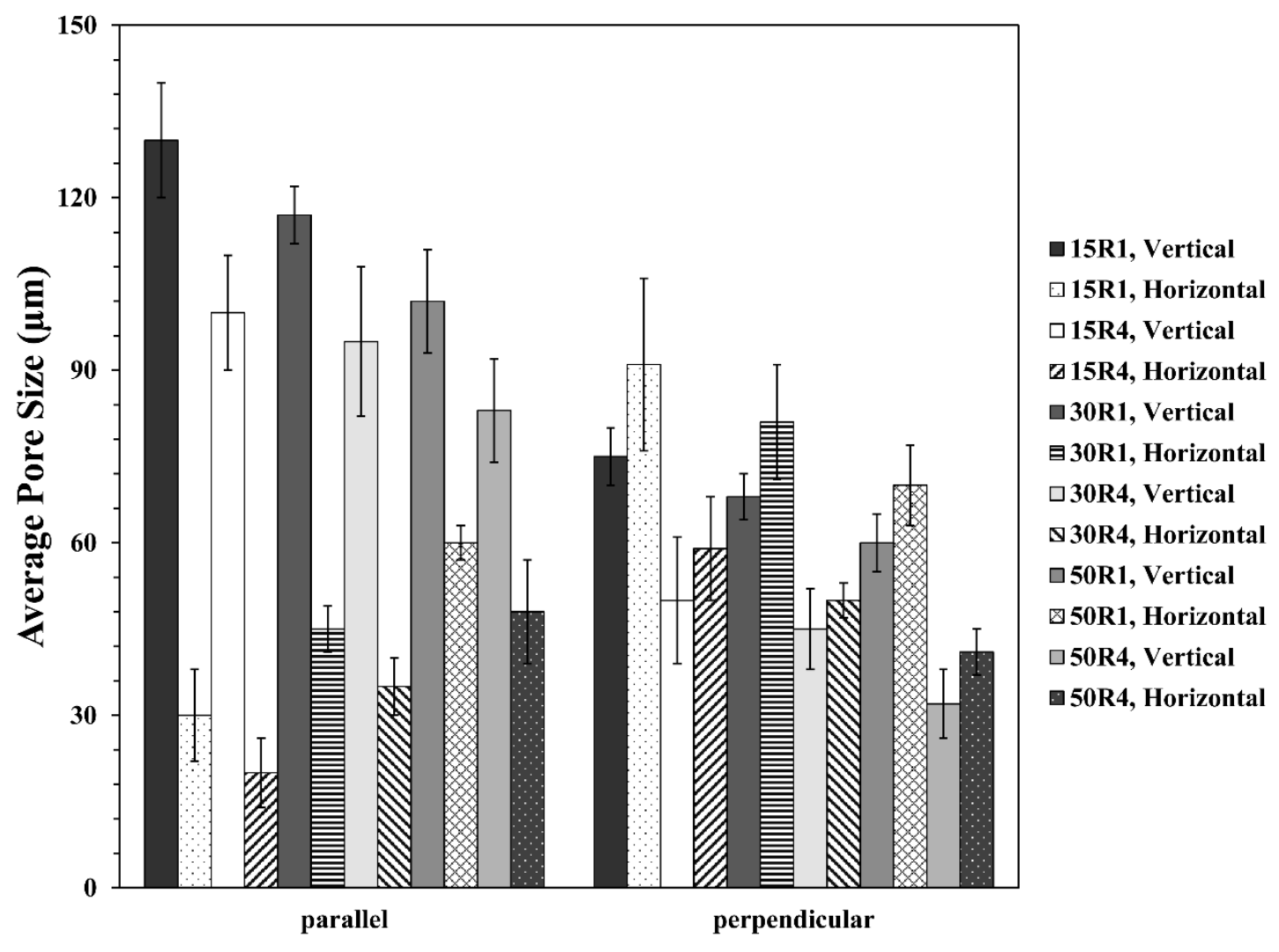



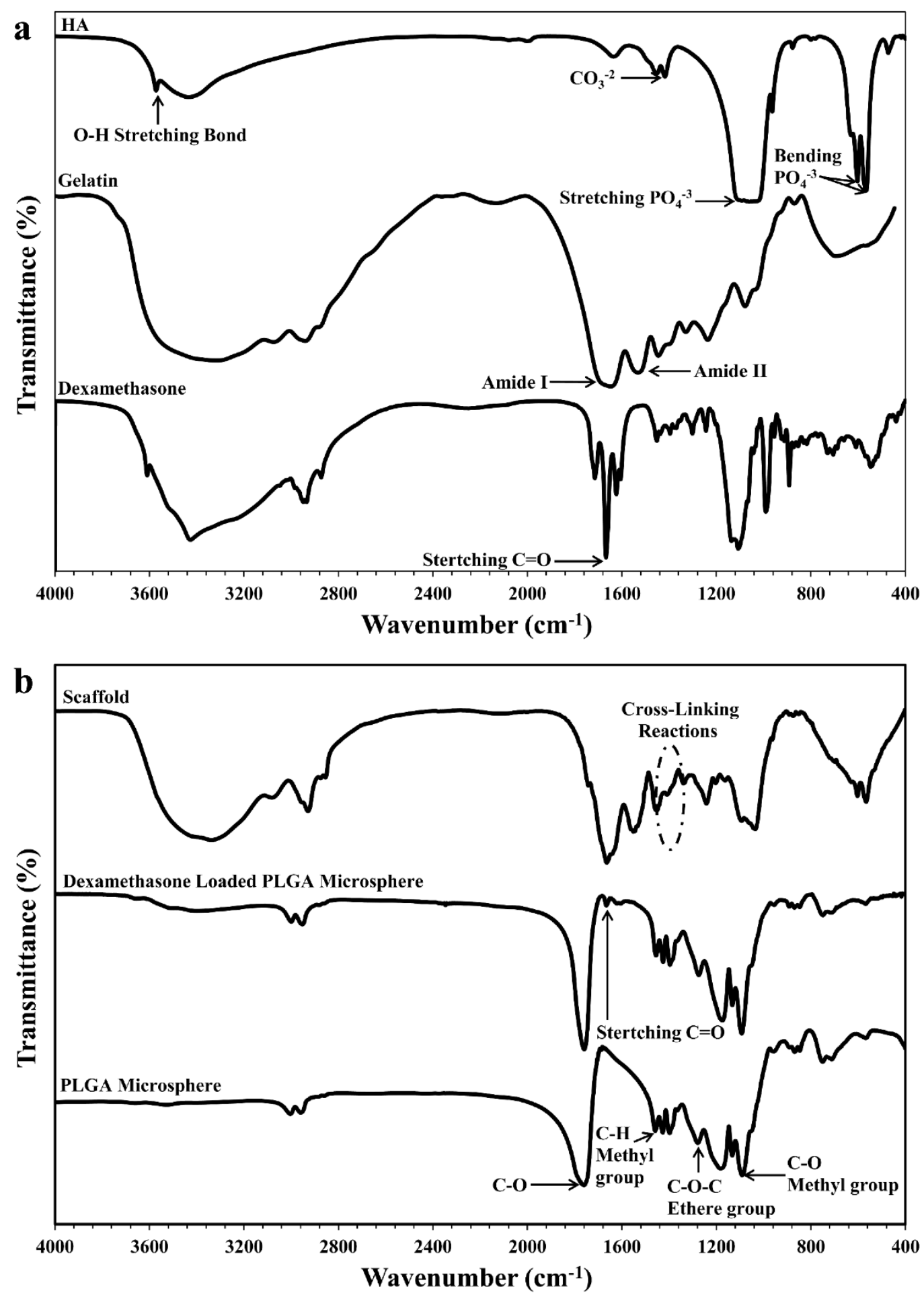


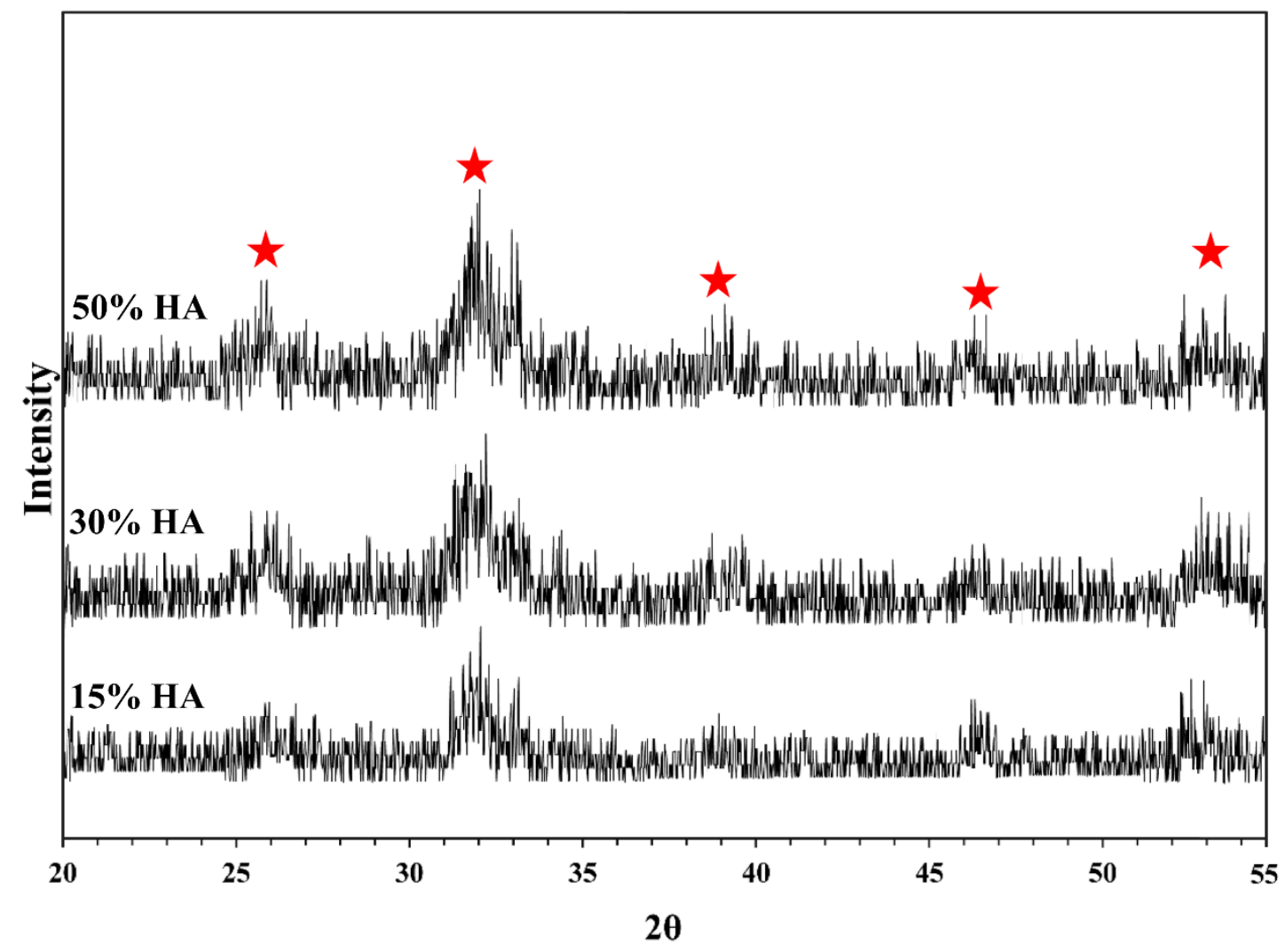




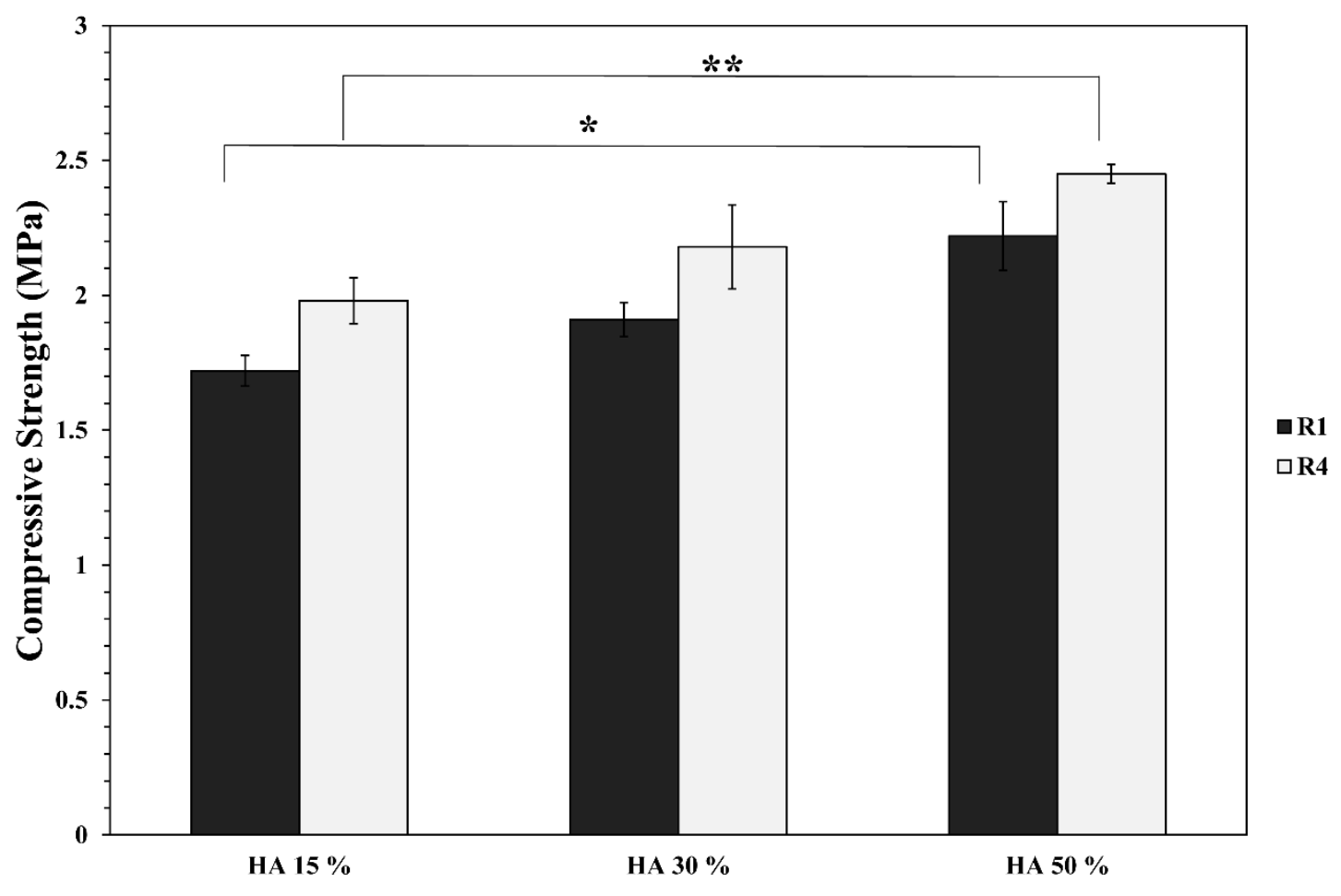




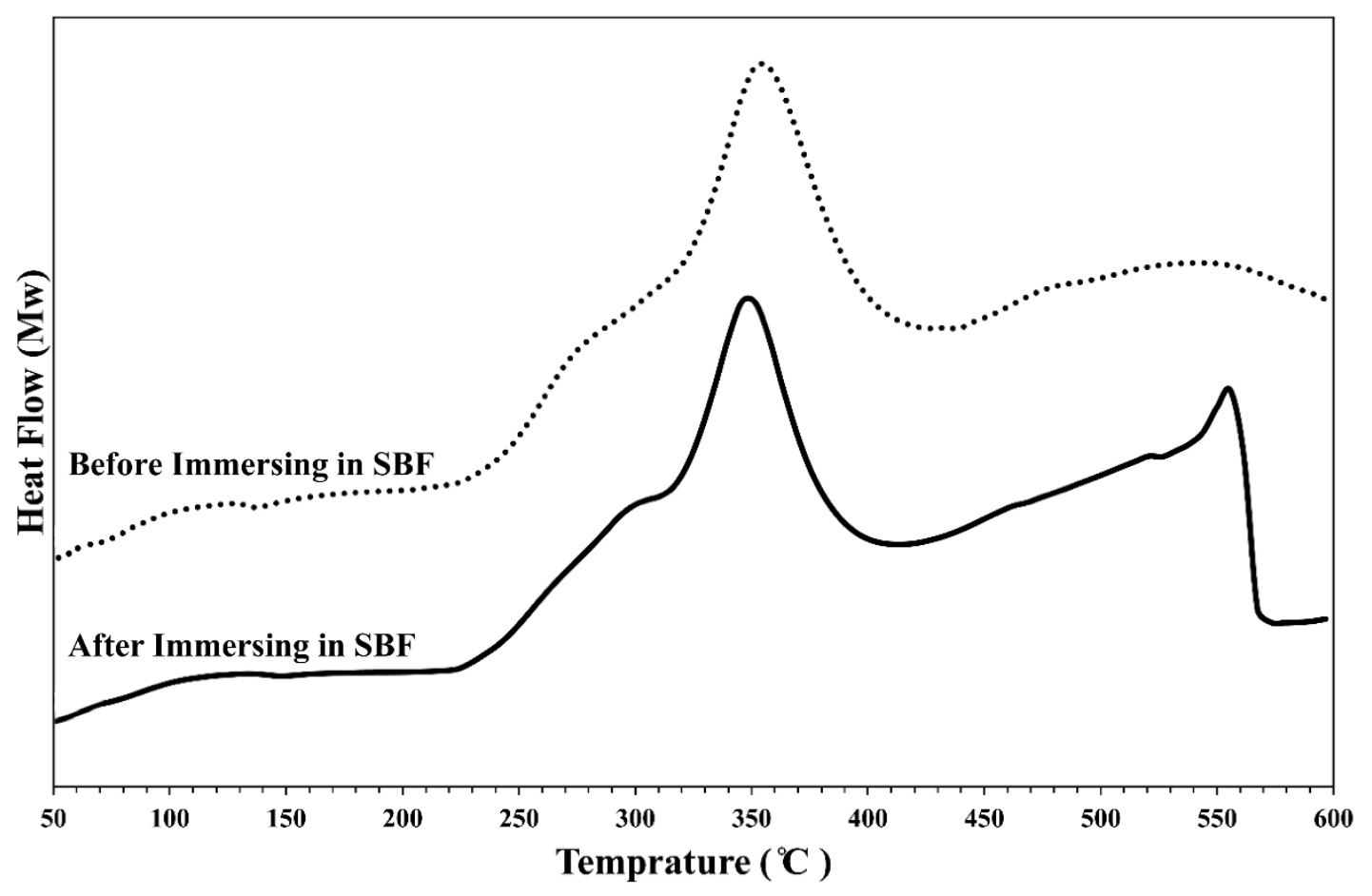




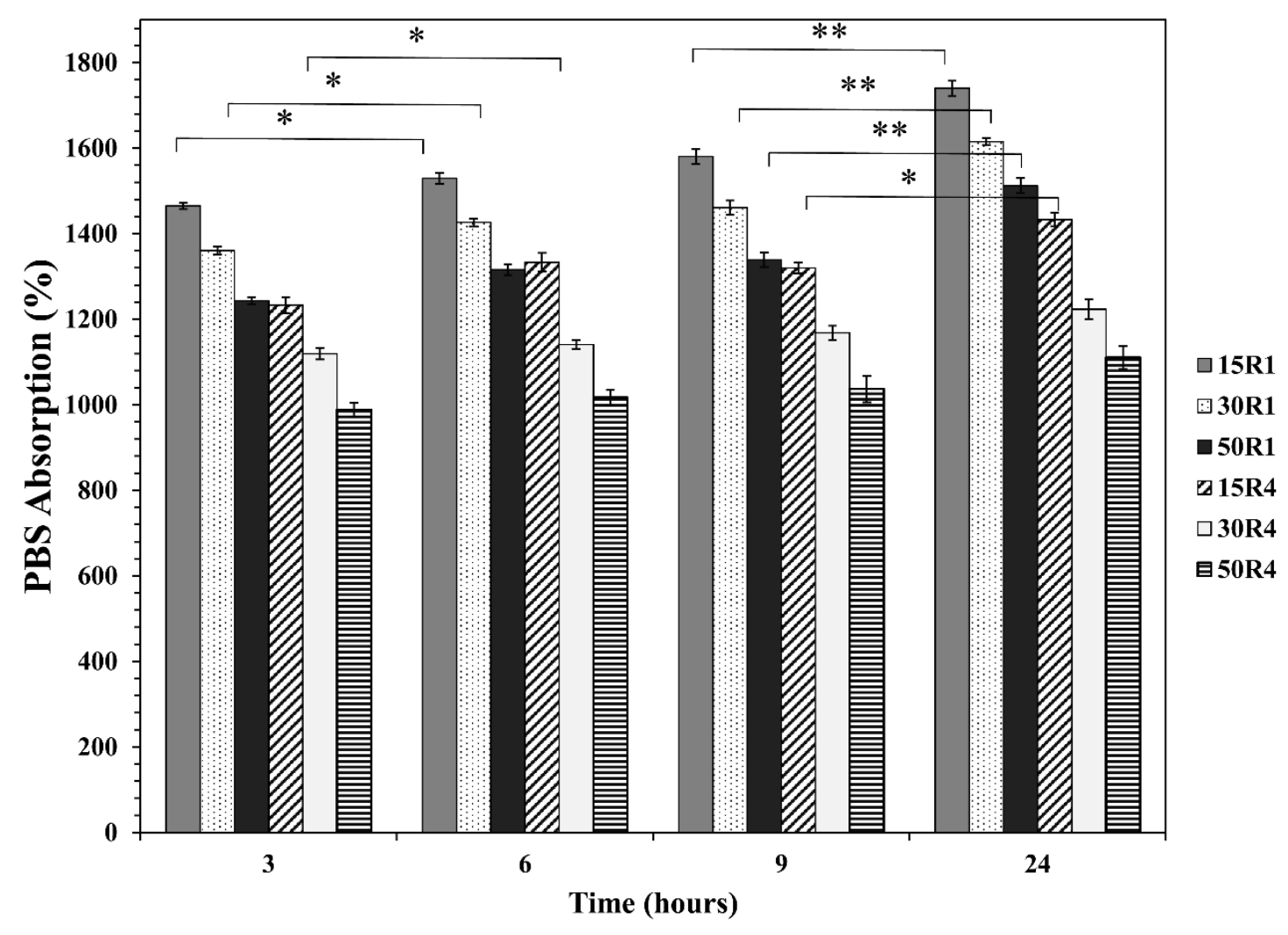




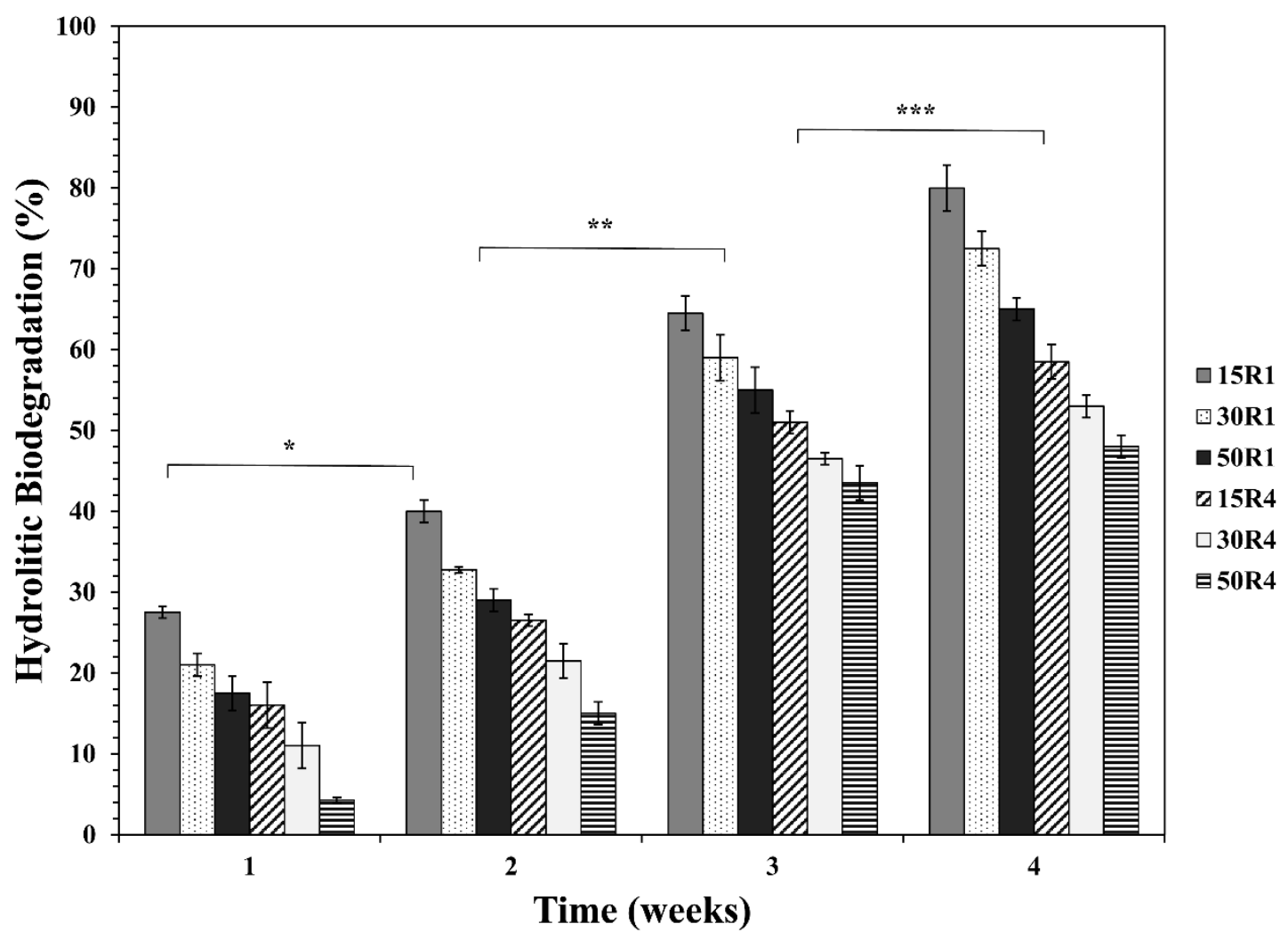




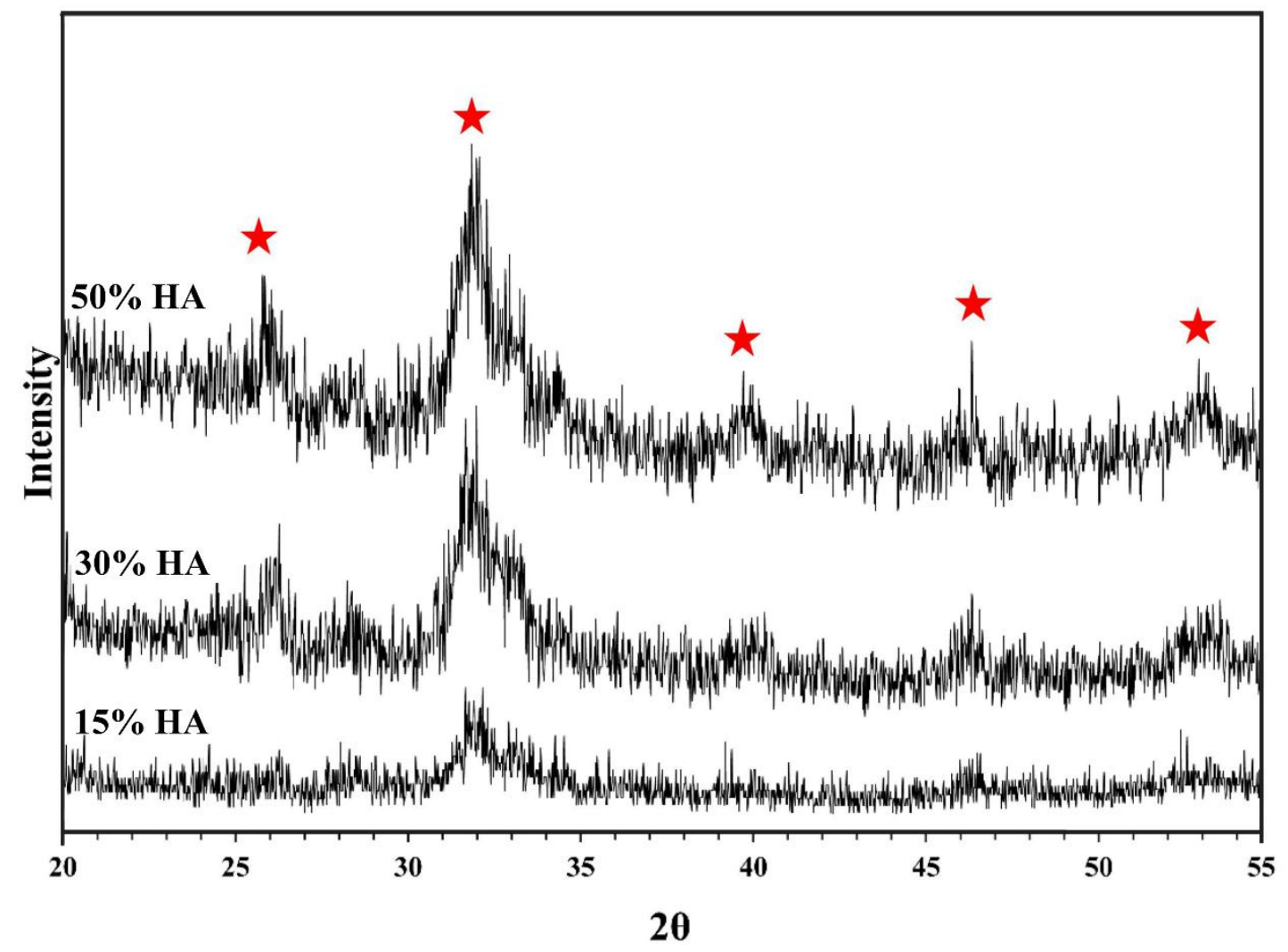




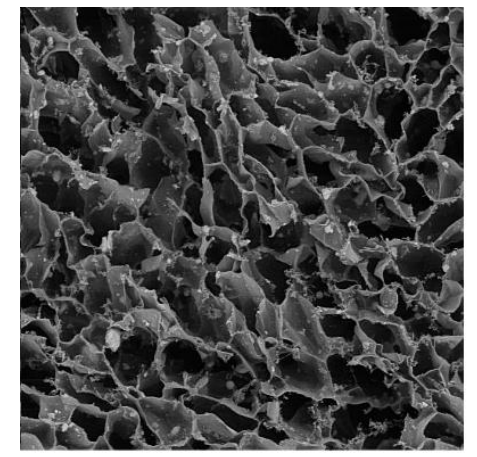

15R1

$100 \mu \mathrm{m}$

$\mathrm{Ca} / \mathrm{P}($ weight ratio $)=1.96$

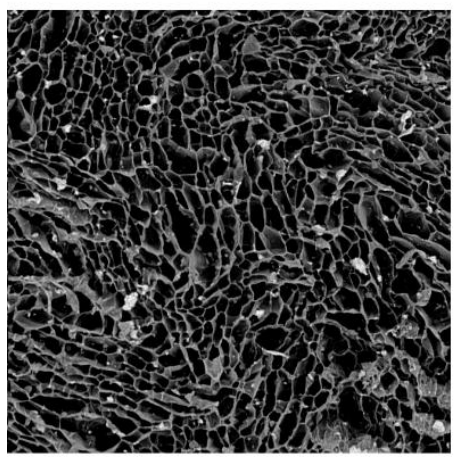

15R4

$100 \mu \mathrm{m}$

$\mathrm{Ca} / \mathrm{P}($ weight ratio $)=1.91$

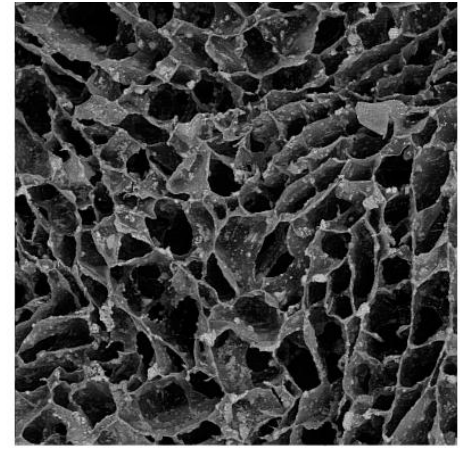

30R1

$100 \mu \mathrm{m}$

$\mathrm{Ca} / \mathrm{P}($ weight ratio $)=\mathbf{2 . 1 2}$

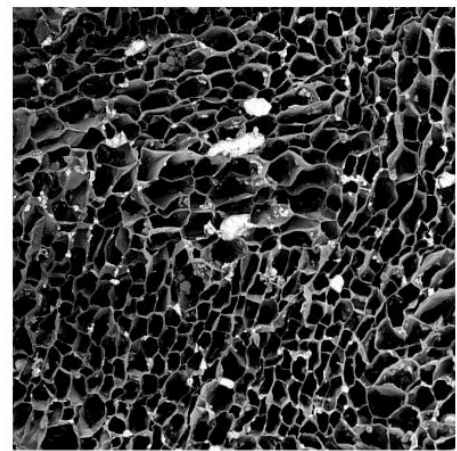

30R4

$100 \mu \mathrm{m}$

$\mathrm{Ca} / \mathbf{P}($ weight ratio $)=\mathbf{2 . 0 1}$

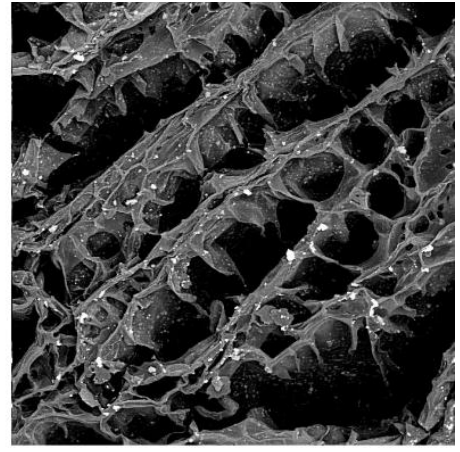

50R1

$100 \mu \mathrm{m}$

$\mathrm{Ca} / \mathrm{P}$ (weight ratio $)=\mathbf{2 . 2 6}$

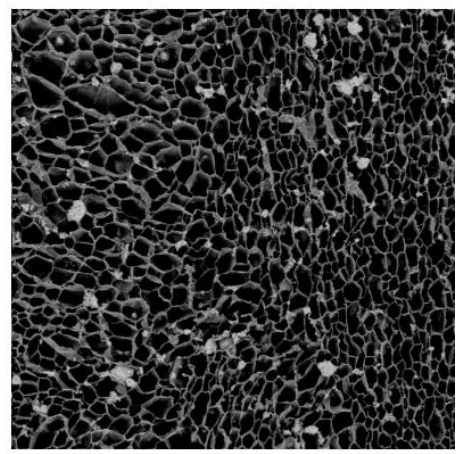

50R4

$100 \mu \mathrm{m}$

$\mathrm{Ca} / \mathrm{P}($ weight ratio $)=2.19$ 


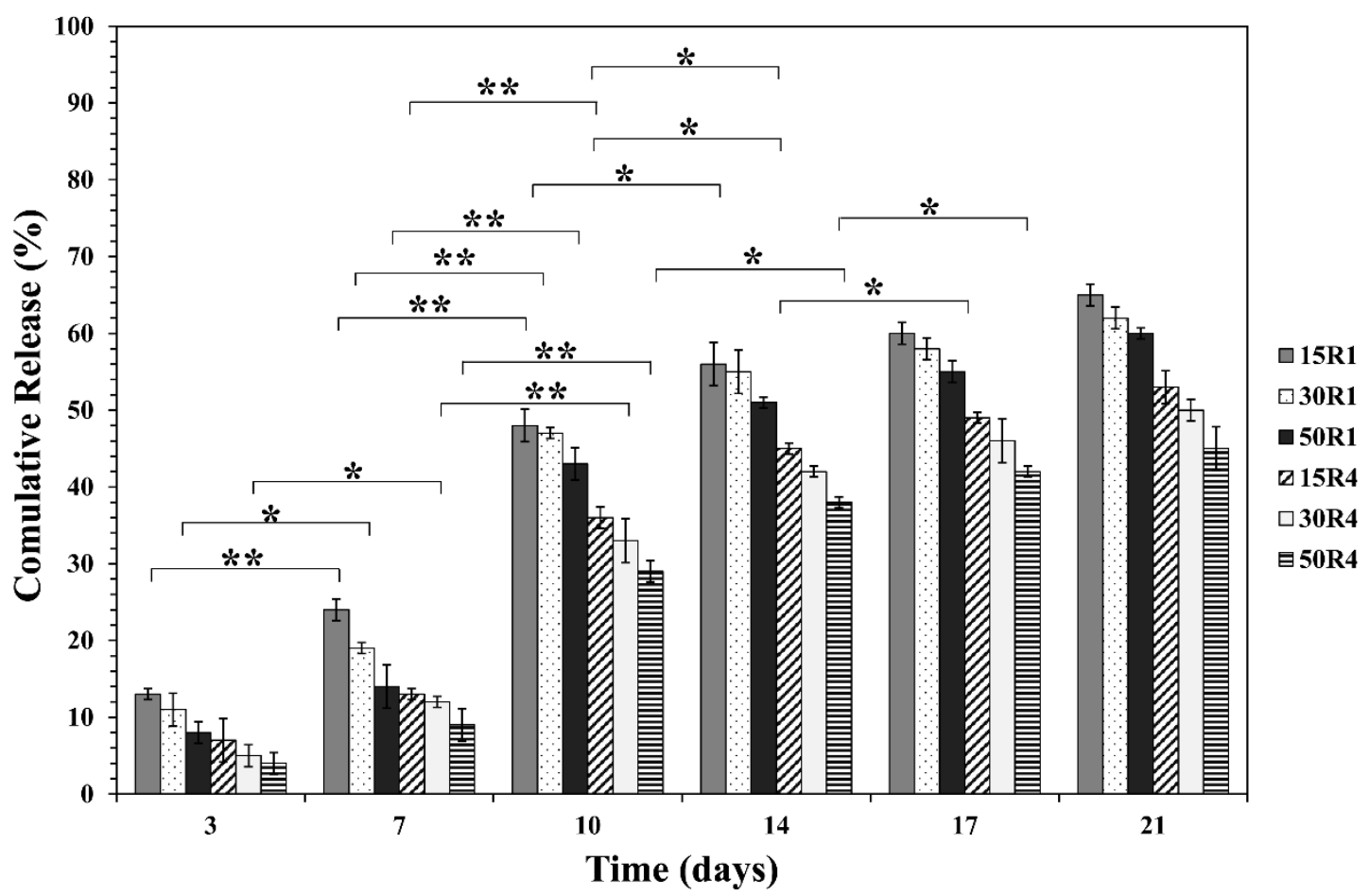




\section{Table 1: Abbreviation of synthesis scaffolds.}

Code Types of Scaffolds

15R1 Hydroxyapatite (15\%)-gelatin scaffolds-dexamethasone loaded PLGA microspheres freezing rate $=1{ }^{\circ} \mathrm{C} / \mathrm{min}$

30R1 Hydroxyapatite (30\%)-gelatin scaffolds, dexamethasone loaded PLGA microspheres freezing rate $=1{ }^{\circ} \mathrm{C} / \mathrm{min}$

50R1 Hydroxyapatite (50\%)-gelatin scaffolds, dexamethasone loaded PLGA microspheres freezing rate $=1{ }^{\circ} \mathrm{C} / \mathrm{min}$

15R4 Hydroxyapatite (15\%)-gelatin scaffolds, dexamethasone loaded PLGA microspheres freezing rate $=4{ }^{\circ} \mathrm{C} / \mathrm{min}$

30R4 Hydroxyapatite (30\%)-gelatin scaffolds, dexamethasone loaded PLGA microspheres freezing rate $=4^{\circ} \mathrm{C} / \mathrm{min}$

50R4 Hydroxyapatite (50\%)-gelatin scaffolds, dexamethasone loaded PLGA microspheres freezing rate $=4^{\circ} \mathrm{C} / \mathrm{min}$ 

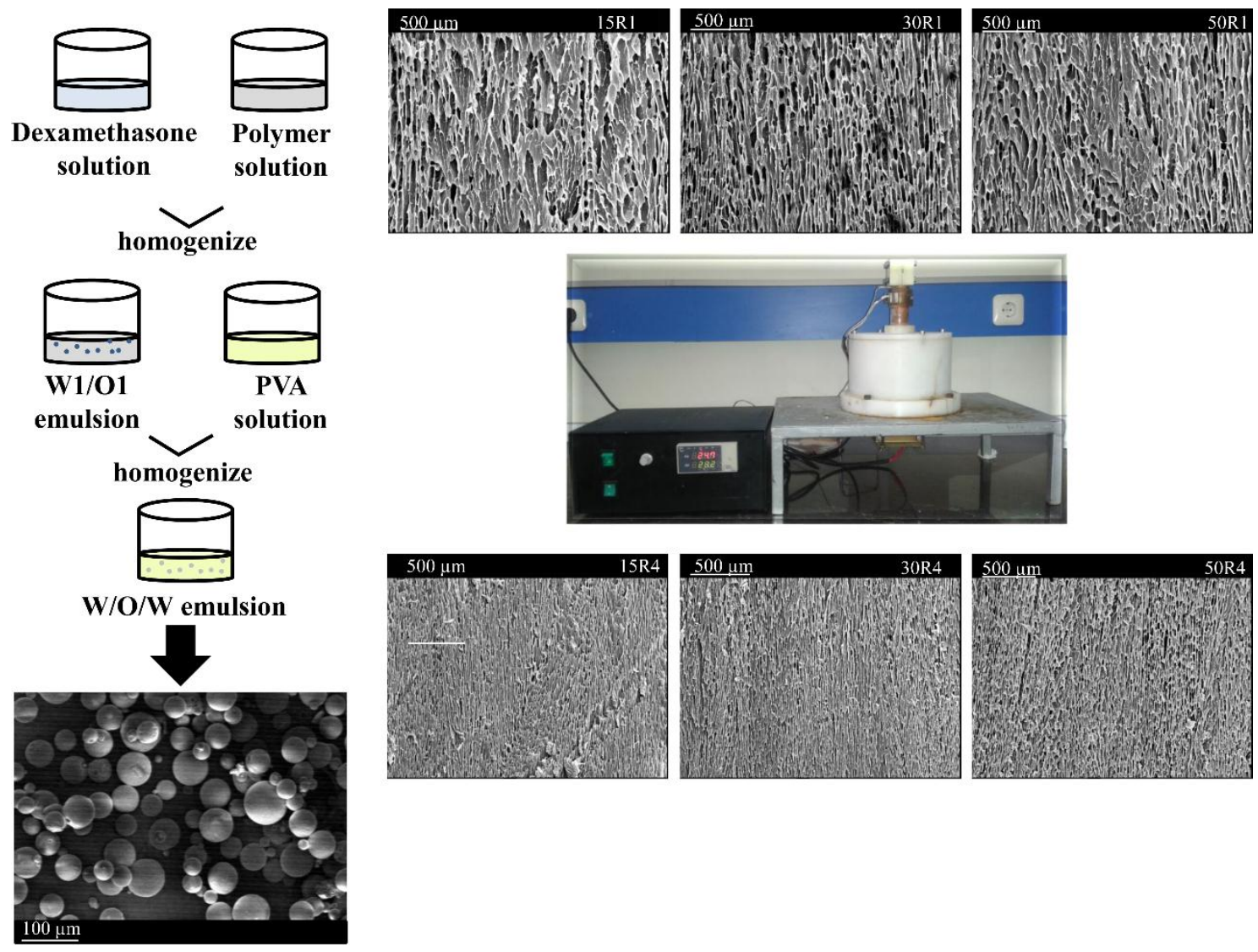